\title{
Numerical Simulation and Analysis of the April 2013 ChicagoFloods
}

\author{
Edwin Campos and Jiali Wang \\ Argonne National Laboratory, Argonne, Illinois, USA \\ Submitted to the Journal of Hydrology \\ Special Issue on Radar Hydrology
}

Second Revision version on August24,2015

Keywords: Chicago, floods, atmospheric rivers, WRF, radar

Corresponding author address: Dr. Edwin Campos, Argonne National Laboratory, 9700 South

Cass Avenue, GSS/EESA, Building 221, Argonne, IL 60439-4854.E-mail: ecampos@anl.gov . 


\section{Abstract}

2 The weather eventassociated to record Chicago floods on April 2013 is investigatedby using

3 the Weather Research and Forecasting(WRF) model. Observations at Argonne National

4 Laboratory and multi-sensor (weather radar and rain gauge) precipitation data fromthe National

5 Weather Service were employed to evaluate the model's performance. The WRF model

6 capturedthe synoptic-scale atmospheric features well, but the simulated24-h accumulated

7 precipitation and short-period temporal evolution of precipitation over the heavy-rain regionwere

8 less successful. To investigate the potential reasons for the model bias, foursupplementary

9 sensitivity experiments using various microphysics schemes and cumulus parameterizations were

10 designed. Of the five tested parameterizations, the WRF Single-Moment6-class (WSM6)graupel

11 scheme and Kain-Fritsch (KF) cumulus parameterization outperformed the others, such as Grell-

12 Dévényi(GD) cumulus parameterization, whichunderestimated the precipitation by $30-50 \%$ on a

13 regional-average scale. Morrison microphysics and KF outperformed the othersfor the spatial

14 patterns of 24-h accumulated precipitation. The spatial correlation between observation and

15 Morrison-KF was 0.45, higher thanthose for other simulations.All of the simulations

16 underestimated the precipitation over northeastern Illinois (especially at Argonne)during

17 0400-0800 UTC 18 April because of weak ascending motion or small moisture. All of the

18 simulations except WSM6-GD also underestimated the precipitation during 1200-1600 UTC 18

19 April because of weak southerly flow. 


\section{Introduction}

The worst floods experienced by Chicago area residents in the last three decades occurred

22 from the precipitation event on 18 April 2013. On that day, Illinois was declared in a State of

23 Emergency, and by 21 April 2013, forty-four of its 102 counties were designatedDisaster

24 Areas.The heaviest 24-h accumulated rainfall (recorded by National Weather Service (NWS)

25 observatories on 18 April 2013)reached $201.4 \mathrm{~mm}, 171.1 \mathrm{~mm}$, and $136.4 \mathrm{~mm}$ across Illinois,

26 Iowa, and Missouri, respectively.As a reference, the average 24-h accumulated rainfall for April

27 at Chicago O'Hare International Airport is $85.9 \mathrm{~mm}$ (from 1981-2010 rainfall observations

28 available at the National Climatic Data Center (NCDC)).However, by 19April 2013, the Chicago

29 O'Harestation hadrecorded the record-breaking amount of $199.1 \mathrm{~mm}$ of rain. Similarly, the

30 Mississippi River crested at $10.8 \mathrm{~m}$ (1.7 $\mathrm{m}$ above flood stage), and the Illinois River crested in

31 Peoria, Illinois, at $8.95 \mathrm{~m}$, breaking the record of $8.78 \mathrm{~m}$ set in 1943 and $4.55 \mathrm{~m}$ above the

32 historical normal river stage (NWS, 2013). Considering damage costs records since 1987, this

33 event ranksamong the top-five worst floods in Chicago history, according to the Wall Street

34 Journal (WSJ,2013).

35 The flooding event and heavy precipitation caused major disruptionto services and people 36 around the Chicago region. The NWS reported that the East Branch of the DuPage River was at

$376.37 \mathrm{~m}$ on 18 April, $0.43 \mathrm{~m}$ higher than flood stage, and the river continuedto rise to $6.92 \mathrm{~m}$ by 3819 April.

39 Interestingly enough, the frequency of flood-producing precipitation events has increased 40 during the past six decades, with the largest increase occurring in a belt extending from the 41 southwestern United States, across the Great Plains and middle Mississippi River valley, and into 
42 the Great Lakes basin (Kunkel et al., 1999; 2003; 2013). Moreover, the frequency of extreme

43 precipitation is projected to increase in the future, according to multi-CMIP5(Coupled Model

44 Intercomparison Project) predictions (Wuebbles et al., 2013) under different scenarios.Therefore,

45 this heavy-rain event deserves a morecomprehensive analysis. It is a golden case for testing

46 weather analysis and prediction techniques that could fill understanding gaps related to high-

47 impact floods.

48 Unfortunately, the requiredhigh-resolution observational datasetsare ill-assorted and eclectic.

49 For example, the NCDC datasets have only daily rainfall values for 2013, while the Tropical

50 Rainfall Measuring Mission (TRMM, 2014) archives have 3-h precipitationarea values at 32-km

51 spatial resolution - too coarse to be used for such a highly localized and intense rainfall event.

52 The alternative is to use high-resolution model datasets, which are generated by computationally-

53 expensive weather simulations, require model scheme optimization among a multitude of

54 available parameterizations, and need model output validation using large amounts of

55 observational data.

56 With that in mind, the purpose of this work consists of identifying optimal modeling designs

57 for simulating the extreme spring floods of 2013 over Chicago. The scope corresponds to a two-

58 fold analysis of the event. In its first part, this study describes the event from the synoptic scale,

59 mesoscale and precipitation microphysical perspective, using a comprehensive set of

60 observational datasets in and around Argonne National Laboratory. These datasets include

61 observations from four S-band WSR-88D radars and a UHF-band vertically-pointing radar, as

62 well as from Precipitation-Size-Distribution and rain-gauge sensors. In the second part, the study

63 attempts to reproduce the heavy rainfall observations by using numerical simulations from the

64 WRF-ARW model at a high temporal and spatial resolutions (10min and $3 \mathrm{~km}$, respectively) 
65 with nested domains. Sensitivity experiments using different microphysics schemes and cumulus

66 parameterizations in WRF-ARW are analyzed to investigate optimal simulation designs for the

67 event. Performance of the different modeling designsare evaluated for the synoptic scale,

68 mesoscale, and local scale by using a comprehensive set of observational in-situ and radar

69 datasets gathered at Argonne National Laboratory and across Illinois, Iowa, and Missouri.

70 This is one of the first studiesin the scientific peer-reviewed literature about this flood event.

71 Therefore,wehope that its analyses will serve as a reference for the selection of numerical

72 physical parameterizations and model performance for future numerical simulations ofhigh-

73 impactfloods overthe U.S. Midwest.

\section{2. Methods}

\section{2.1.Datasets}

76 To analyze the synoptic-scale atmospheric circulation associated with this heavy-rain event,

77 the study exploredgeopotential height at $500 \mathrm{hPa}$, wind vector at $850 \mathrm{hPa}$, and precipitable water

78 and sea level pressure from the National Center for Environmental Prediction Final reanalysis

79 (NCEP-FNL, National Centers for Environmental Prediction, 2000) at a horizontal resolution of

801.0 degree. In addition, we used relative humidity and horizontal winds at all pressure levels

81 from NCEP-FNL to calculate vertically integrated water vapor transport, as discussed under

82 Analyticssection below.

83 The study also employed hourly precipitation estimates (in $\mathrm{mm} \mathrm{h}^{-1}$ ) gridded at 4-km

84 horizontal resolution over the contiguous United States, available from the National Weather

85 Service River Forecast Centers (NWSRFC 2013). These data are based on a multi-sensor

86 retrieval approach (Kuligowski 1997), in which hourly precipitation estimates from Weather 
87 Surveillance Radar 88 Doppler Next-Generation Radar (WSR-88D NEXRAD) are compared to

88 ground rainfall gauge reports, and a bias is calculated and applied to the radar field. The radar

89 and gauge fields are combined into a "multi-sensor field" that is quality controlled hourly. In

90 areas with limited or no radar coverage, satellite precipitation estimates are incorporated into this

91 multi-sensor field.

92 Daily accumulation rain-gauge measurements were compiled by NOAA-NCDC during the

93 flood event. These measurements include 635 rain-gauge stations in Iowa, 715 stations in

94 Illinois, and 565 stations in Missouri. We will use these datasets to evaluate our numerical model

95 outputs of 24-hr accumulated precipitation over the region.

96 A suite of advanced meteorological instruments was in operation during the flood event at

97 the Argonne National Laboratory weather observatory $\left(41^{\circ} 42^{\prime} 04^{\prime \prime} \mathrm{N}, 87^{\circ} 59^{\prime} 42^{\prime \prime} \mathrm{W}, 230 \mathrm{~m}\right.$

98 above sea level;Campos 2013). Because of its relevance to the present study, we selected two of

99 its datasets for analysis of the WRF-ARW simulations at high temporal resolutions.

100 The first set of Argonne measurements corresponds to rainfall rates from a Particle-Size-

101 Velocity sensor (Parsivel2), a laser-based optical system for measuring size (diameters of 0.2-25

$102 \mathrm{~mm}$ ) and fall velocities $\left(0.2-20 \mathrm{~ms}^{-1}\right)$ for all types of precipitation particles (Jaffrain and Berne

103 2011). Parsivel2 first categorizes the precipitation particles bytype (drizzle, rain, snow, hail, etc.)

104 and then estimates the corresponding rainfall rate at 1-minute time resolution (post-processing 105 not required). The instrument vendor (OTT 2012, p.38) estimates that $0.001 \mathrm{mmh}^{-1}$ is the 106 minimum precipitation intensity detected by Parsivel2, at a rain rate accuracy of $\pm 5 \%$ for liquid 107 precipitation and $\pm 20 \%$ for solid precipitation. 
The second set of Argonne measurements corresponds to vertical profiles of Signal-to-Noise

109 Ratios (SNR), vertical Doppler velocities, and horizontal winds from a UHF(ultrahigh-

110 frequency) radar wind profiler, a radio-basedradar systemfor transmitting and receiving signals at

111 the 915-MHz electromagnetic frequency (UHF band), as described byVaisala(2002a). Radars in

112 the UHF band are sensitive to precipitation particles and turbulence clear-air targets (eddies

113 causing inhomogeneities in the refractive index of the air). The precipitation and clear-air targets

114 are used as tracers for precipitation intensity and wind speed estimates at different heights above

115 the radar.For our case, the SNR and vertical Doppler velocities were obtained from observations

116 of the radar vertical beam, using a pulse length of $2800 \mathrm{~ns}$. Each horizontal wind profile estimate

117 was obtained by processing the returned radar signals from one vertical beam and four oblique

118 beams (north, south, east, and west). This used the continuous wind profile estimates by the

119 LAP-3000 algorithm of the UHF profiler vendor (Vaisala 2002b), representative of periods near

12030 minute at vertical spacing of $193 \mathrm{~m}$, with accuracies on the order of $<1 \mathrm{~ms}^{-1}$ for wind speed

121 and < 10 degrees for wind direction (Vaisala 2002b). During post-processing, we filtered in only

122 the estimatesfrom beams using 2800-ns pulse width, with signal-to-noise ratios $\geq 0 \mathrm{~dB}$.

123 2.2. Analytics

124 During the analysis of the atmospheric circulation at the synoptic scale, we will search for 125 atmospheric rivers that can be associated to the flood event. An atmospheric river is defined as a 126 narrow region of intense vertically-integrated horizontal water-vapor transport (hereafter, 127 integrated vapor transport, [IVT]), which is located in the warm sector of an extratropical 128 cyclone.. The IVT field(in $\mathrm{kg} \mathrm{m}^{-1} \mathrm{~s}^{-1}$ ) is calculated from the surfaceto the $300 \mathrm{hPa}$ level,as 129 follows (Neiman et al. 2008; Lavers and Villarini 2013): 


$$
I V T=\sqrt{\left(\frac{100}{g} \int_{1000}^{300} q u d p\right)^{2}+\left(\frac{100}{g} \int_{1000}^{300} q v d p\right)^{2}}
$$

131 where300 and 1000 correspond to the top and bottom pressures in $\mathrm{hPa}, q$ is the layer-averaged

132 specific humidity in $\mathrm{kg} \mathrm{kg}^{-1} ; u$ and $v$ are the layer-averaged zonal and meridional winds in $\mathrm{m} \mathrm{s}^{-1}$,

133 respectively; $g$ is the acceleration due to gravity $\left(9.8 \mathrm{~m} \mathrm{~s}^{-2}\right)$; and $d p$ is the difference between

134 adjacent model pressure levels in $\mathrm{hPa}$.

135 We calculated the vertical profiles of specific humidity $\left(q\right.$, in $\left.\mathrm{kg} \mathrm{kg}^{-1}\right)$ using the corresponding 136 profiles of temperature $(T$, in Kelvins), pressure $(P$, in $\mathrm{hPa})$, and relative humidity $(R H$, in $\%)$.

137 The reason was that specific humidity profiles were not available in the NCEP-FNL nor in our 138 WRF outputs. For this, we used

$$
e_{s}=6.1078 \exp \left[\frac{17.2693882(T-273.16)}{(T-35.86)}\right]
$$

144 where $q_{s}$ is the saturation specific humidity (in $\mathrm{kg} \mathrm{kg}^{-1}$ ) and $e_{s}$ is the saturation vapor pressure (in $145 \mathrm{hPa})$.

A fundamental metric for comparing observational and simulation datasets is the regional 147 average bias (RAB). We apply the RAB for 24-h accumulated precipitation estimates over 148 different domains or areas,as follows: 
150 where $N$ is the number of rainfall stations or grid cells across the concerned domain or areas, $M$ 151 represent the model simulation, and $O$ corresponds to the observation.

An additional metric, the Site Percent Biases (SPB), will be used later to compare

153 observational and simulation datasets representative of a particular site. Its definition follows:

$$
S P B=\frac{\left(\sum_{\tau} M_{t}\right)-\left(\sum_{\tau} O_{t}\right)}{\sum_{\tau} O_{t}} \times 100
$$

where $t$ is a particulartime in the analysis period $\tau, M$ represent the model simulated rainrate for a

156 particular grid cell near the observation station, and $O$ corresponds to the observed rainrate for a 157 particular station near the model grid cell.

\subsection{Software and Hardware}

The numerical simulations were carried out by using the high-resolution Weather Research

160 and Forecasting model (WRF version 3.3.1), a fully compressible, non-hydrostatic, primitive-

161 equation model with multiple-nesting capabilities to enhance resolution over the areas of interest.

162 The model uses the Eulerian mass coordinate, and it is also referred to as the Advanced Research

163 WRF (ARW) model. The WRF model was chosen for several reasons. The first is thatthe

164 modelis especially suited for the proposed high-resolution simulations,becauseof its nesting 165 capabilities. WRF outputs can also provide critical insight for operational analysis and

166 forecasting of extreme weather events such as the Spring 2013 Chicago Floods. Furthermore, 167 understanding the limitations and applicability of the WRF model for these high-impact weather 168 events is a key goal, as WRF is one of the operational models used by many agencies (including 
169 the US National Weather Service) for public weather forecasting. The model is also widely used

170 for downscaling global climate model simulations (e.g., Leung and Qian 2009; Gao et al. 2012;

171 Tripathi and Dominguez 2013). Therefore, determining its performance in reproducing extreme

172 events is of great interest for research applications.

173 We first set up the WRF model on the Hopper supercomputer of the National Energy

174 Research Scientific Computing Center. This is a facility located at Lawrence Berkeley National

175 Laboratory for the Office of Science in the US Department of Energy. Hopper is a Cray XE6

176 system, with a peak performance of 1.28 Petaflops/sec, 217 Terabytes of memory, 2 Petabytes of

177 disk storage, and 153,216 compute cores. For this part of the study, we used 480 compute cores.

178 We did five sensitivity simulations (explained in the next section): one Control run and four Test

179 runs. Each of these simulations (from Reanalysis input to Domain d03 output) required about

180 1hour and 20 minutes to complete.

For the final setup of the simulations, our WRF model configuration in the Hopper

182 supercomputer was replicated in a faster supercomputer: Edison, the newest supercomputer at

183 the NERSC, is a Cray XC30 with a peak performance of 2.57 petaflops/sec, 133,824 compute

184 cores, 357 terabytes of memory, and 7.56 petabytes of disk storage. This time, we used 600

185 compute cores. We did these simulations using five different initial times and one model

186 parameterizations configuration (explained in the next sections). Each of these simulations (from

187 reanalysis input to domain d03 output) required about one hour (wall clock time) to complete.

\subsection{Modeling configuration}

In order to increase the resolution in the numerical simulations, we configured three nested

190 domains according to Figure 1.All domains were centered over $\left(39^{\circ} \mathrm{N}, 97^{\circ} \mathrm{W}\right)$, and had 38 
191 vertical (pressure) layers, from the terrain surface up to the $100 \mathrm{mb}$ level. The first domain (d01)

192 was the coarsest mesh, having $180 \times 106$ grid points (in the west-east and south-

193 northdirections), for a horizontal grid spacing of $27 \mathrm{~km}$, and time resolution of 3 hours. The

194 second domain(d02, is nested within domain d01)had $199 \times 184$ grid points at 9-km grid

195 spacing, and time resolution of 1 hour. The fine-mesh domain (d03)had $250 \times 220$ points at 3-km

196 grid spacing, and time resolution of10 minutes. Domain d03 covered Illinois, Iowa, and

197 Missouri, where the heaviest precipitation occurred on 17-19 April 2013. The NCEP-

198 FNLdataset (at 1-degree horizontal resolution, and 6-hours time resolution) was used as initial

199 and lateral boundary condition for the d01 domain. The model simulations over the three domains

200 started at 1200 UTC on 15 April 2013 and were integrated for 96 h (i.e. 4-days simulation

201 horizon), ending at 1200 UTC on 19 April 2013.

202 In order to reduce the numerical artifacts in the simulation of non-resolved scales, we 203 appliedthe spectral nudging technique (Miguez-Macho et al., 2004, 2005; Wang and Kotamarthi 204 2013) to WRF outputs over the outer domain (d01). In particular, we nudgedthe fields of 205 horizontal winds, temperature, and geopotential height, at the levels of $850 \mathrm{hPa}$ and above. For 206 the wavenumbers in the zonal and meridional directions we used 3 and 2, respectively. In other 207 words, over the domain d01 we have 3 nudging points in the $\mathrm{x}$ direction and 2 nudging points in 208 the y direction. The nudging coefficient was $3 \times 10^{-4} \mathrm{~s}^{-1}$. Nudging was conducted every $6 \mathrm{~h}$, 209 consistent with the frequency of the NCEP-FNL data.

210 For studying the simulation skill as a function of model spin-up time (i.e. the simulation 211 period before we start analyzing the results), we varied the initial time in five additional model 212 simulations. These additional simulations run with 4-days simulation horizons (as before), and 
213 started at 1800 UTC 14 April 2013, 0000 UTC 15 April 2013, 0600 UTC 15 April 2013, 1800

214 UTC 15 April 2013, and 0000 UTC 16 April 2013.

\section{2.5. Model parameterizations}

216 The WRF model has multiple parameterization schemes for each of its five main physical

217 packages: cumulus parameterizations, microphysics schemes, short- and longwave radiation

218 schemes, planetary boundary layer (PBL) schemes, and land surface processes. Many previous

219 studies (e.g., Gallus and Bresch 2006; Rajeevan et al. 2010; Liu et al. 2011; Li et al. 2013) have

220 demonstrated in general terms that the selection of the physics and parameterization options can

221 affect modeling of rainfall; among these, the microphysics and the cumulus parameterizations

222 are the most important factors for bias in the modeled precipitation (Fowler and Randall 2002;

223 Kumar et al. 2008; Hong et al. 2010; Rajeevan et al. 2010; Collis et al. 2013), while other factors

224 (parameterizations) have only moderate to weak impacts on the modeled precipitation results

225 (Liu et al. 2011).

226 With that in mind, five simulations were performed with different microphysics schemes and 227 cumulus parameterizations (Table 1) to investigate the impacts of various 228 physicsparameterizations on simulation of the heavy-rain event on 18 April 2013.

229 In the Control simulation, the Morrison microphysics scheme (Morrison) and the Grell230 Dévényi (GD) ensemble cumulus parameterization were employed. The Morrison

231 scheme(Morrison et al. 2009), a double-moment scheme, considers six species of water (vapor,

232 cloud droplets, cloud ice, rain, snow, and graupel/hail). Prognostic variables of the Morrison

233 scheme include both number concentrations and mixing ratios of cloud ice, rain, snow, and 234 graupel/hail and mixing ratios of cloud droplets and water vapor. This allows for a robust 
235 treatment of the particle size distributions and is a key for calculating microphysical process rates

236 and cloud/precipitation evolution.The GD scheme (Grell and Dévényi 2002) employs a variety

237 of mass flux and closure assumptions, feedback assumptions, and trigger functions at each grid

238 point.

239 To investigate sensitivity to cumulus parameterizations, the GD scheme was replaced by the

240 Kain-Fritsch cumulus parameterization (KF; Kain and Fritsch 1990, 1993; Kain 2004) in Test 1.

241 The characteristics and differences between KF and GD cumulus parameterizations have been

242 well summarized by Taylor (2011).

243 For Test 2, the WRF Double-Moment 6-class scheme (WDM6; Hong et al. 2010) was used

244 with the KF cumulus parameterization. For the WDM6 scheme, the rain category is predicted

245 with two moments - total mass and number concentration (Hong et al. 2010; Molthan 2011).

246 The WDM6 has been already evaluated on an idealized two-dimensional thunderstorm test bed

247 (Lim and Hong 2010) and for a squall line case over the U.S. Great Plains (Hong et al. 2010).

248 To further investigate the model sensitivity to microphysics schemes, the Test 3 experiment

249 was designed with the WRF Single-Moment 6-class (WSM6) graupel scheme (Hong et al. 2004)

250 and the GD ensemble cumulus parameterization. The WSM6 was designed similarly to the

251 WDM6, except that the rain category is predicted with one moment (Hong et al. 2010; Molthan

252 2011).

253 The WSM6 microphysics scheme consists of vapor, cloud ice, cloud water, rain, snow, and

254 graupel processes suitable for high-resolution simulations. Numerous reports evaluating the

255 performance of the WRF with WSM6 microphysics include weather phenomena such as

256 convective-system weather over the central United States (James et al. 2009), a hurricane over 
257 the Atlantic (Li and Pu 2008), heavy rainfall over East Asia (Shin and Hong 2009), and polar 258 weather (Powers 2007). These studies demonstrate that the WSM6 scheme in WRF reproduces 259 precipitating convection and associated meteorological phenomena with reasonable accuracy. 260 Liu et al. (2011) tested seven microphysics schemes suitable for high-resolution simulation and 261 found the Morrison et al. (2009) and Thompson et al. (2004; 2008) microphysics schemes to be 262 superior (in handling winter precipitation) than the WRF single-moment and double-moment 263 microphysics schemes. Liu et al. (2011) found similar performance (when compared to 264 precipitation observations) in the Morrison et al. (2009) and Thompson et al. (2004; 2008) 265 schemes.

266 With that in mind, one additional experiment, named Best in Table 1 (due to its closest 267 agreement with NWS RFC and NCDC observational datasets, as discussed later in subsection 268 3.3.1), was designed with the WSM6 scheme (Hong et al. 2004) and the K-F cumulus 269 parameterization (Kain and Fritsch 1990, 1993; Kain 2004) for further evaluation 270 onparameterization sensitivity.

271 The other physical schemes applied,unchanged,in this study include the Yonsei University 272 PBL scheme (Noh et al. 2003), aland surface model (Chen and Dudhia 2001), and the Rapid 273 Radiative Transfer Model for general circulation models longwave and shortwave schemes 274 (RRTM 2013; Iacono et al. 2008). The cumulus parameterization was turned off over the inner 275 domain (d03), because its resolution is able to resolve the cumulus scale. 


\subsection{Event description}

278 Figure 2presents the 24-h accumulated precipitation field, ending at 1200 UTC 18 April 279 2013, as estimated by the NWS RFC 2013 multi-sensor product across the contiguous United

280 States. This shows a southwest-to-northeast belt that extended across Missouri, Iowa, and Illinois 281 with estimated precipitation up to $100-150 \mathrm{~mm}$.

282 The atmospheric conditionsthat led tothe corresponding floodsare discussed below.These 283 include therelatively wet conditions during the first 16 days of April 2013, which set the stage 284 for potential flooding. In addition, a strong stationary frontal system, a low-level jet from the 285 Gulf of Mexico, and a strong ridge to the east of the flooded areas pushed a plume of deep 286 moisture and intenseprecipitable water into the mid-Mississippi valley and the Great Lakes 287 region.

288 First, we use the NCEP-FNL reanalysis datasets for anexamination on the synoptic 289 meteorology aspects of the event. Figure 3provides a classic analysis, with magnitudes plotted as 290 black isolines or wind barbs, and April-2013 anomalies plotted as color shades. Note the 291 downstream ridge with an upstream trough extending from $110^{\circ}$ to $100^{\circ} \mathrm{W}$ and from $34^{\circ}$ to $50^{\circ}$ $292 \mathrm{~N}$ at $500 \mathrm{hPa}$ (Fig. 3a). Strong southwesterly flow (at a speed of $40-50 \mathrm{~ms}^{-1}$, ahead of the trough) 293 was instrumental in creatingan ascending motion over the Midwest.Alow-level southerly jet with 294 wind speed around $24 \mathrm{~ms}^{-1}$ at $850 \mathrm{hPa}$ (red area in Fig. 3b, corresponding to wind speed 295 anomalies of $8 \mathrm{~m} \mathrm{~s}^{\wedge}-1$ or larger) brought a plume of moisture into the region, with $30-40 \mathrm{~mm}$ of 296 precipitable water at 0600UTC 18 April(Fig. 3c).A surface low-pressure area between two high- 
297 pressure zones over the Northwest and Northeast (Fig. 3d)sustained and strengthenedthe low298 pressure zone.

299 In addition, when we calculated the anomalies of these circulation patterns from the meansfor 300 all ofApril 2013 (color shades in Fig. 3), we found negative geopotentialheight anomalies 301 (100-200 m) near the trough and positive anomalies (100-200 m) near the ridge at 500 $302 \mathrm{hPa}$.Strong southerlyflow anomalies $\left(16-24 \mathrm{~m} \mathrm{~s}^{-1}\right)$,positive precipitable water anomalies $(>15$ $303 \mathrm{~mm}$ ), and negative sea level pressure anomalies (8-16 hPa)from the Gulf of Mexico to Lake 304 Michigan werealso obtained. These anomalies strengthen moisture convergence at the lower 305 level and divergence at the upper level, which together induced the heavy rain over the 306 Midweston 18 April 2013.

307 Similar large scale patterns (as in Fig. 3) were obtained for this event by the ECMWF ERA 308 Interim daily reanalysis (Dee et al., 2011) for 500hPa geopotential height and its anomalies, 850 $309 \mathrm{hPa}$ winds and its anomalies, and for sea level pressure and its anomalies. The precipitable water 310 and its anomalies were about $5 \mathrm{~mm}$ larger in the NCEP-FNL outputs than in the ECMWF ERA 311 Interim outputs (not shown).

312 A modernized analysisof the event can be done by applying Equation (1) to the NCEP-FNL 313 dataset. Figure 4provides the corresponding IVT fields at 06 and 12 UTC on 18 April 2013, 314 which indicate that the atmospheric circulation at the synoptic scale was characterized by an 315 atmospheric riverover theheavy rainfallregion.With respect to the 31-year IVT climatology of 316 annual-maxima spring floods due to atmospheric rivers for our region (Lavers and Villarini, 317 2013b, Fig. 1), the atmospheric river in our Chicago flood was of extremeIVT intensity. For 318 example, the maximum value on 1200 UTC 2013 Apr 18 (Fig. 4 bottom) is $1115 \mathrm{~kg} \mathrm{~m}^{-1} \mathrm{~s}^{-1}$, 
319 greater than the maximum level of the 32-yearclimatological distribution for April (Lavers and

320 Villarini, 2013, their figure 1). Therefore, one can argue that the atmospheric-river intensitywas a

321 veryrelevant factor for this event.

322 It is common to observe atmospheric rivers feeding into mesoscale convective systems.

323 However, from our analyses of convective available potential energy from the NCEP-FNL

324 dataset, between 2013 April 171800 UTC and April 181200 UTC (not shown), we cannot find

325 any direct link between a mesoscale convective system and these Chicago-area floods.

326 Second, we use radardatasets for an examination on the mesoscale meteorology aspects of 327 the event. Figure 5presents a composite of the equivalentreflectivity factor field using 328 observations by the NEXRAD WSR-88D radars in the Chicago region and Argonne's Python329 ARM Radar Toolkit (Py-ART, 2014). The left panel shows equivalent radar reflectivity factors 330 (in $\mathrm{dBZ}$, for color scale at the top) mapped at 2.5-km height above the ground, derived from 331 observations by four NEXRAD WSR-88D radars (KLOT, KILX, KDVN, KMKX)at0922 UTC 33218 April 2013. The red dashed cross is centered at the Argonne Weather Observatory. Right 333 panels plot constant-latitude (top) and constant-longitude (bottom) slides centered at Argonne. 334 Here, equivalent radar reflectivity factors (on the same color scale as in the left panel) are 335 mapped as a function of height (in kilometers above the ground) and horizontal distance (in 336 kilometers from the Argonne Weather Observatory). One can notice the predominance of 337 widespread stratiform precipitation in these plots.

338 Even though the melting layer was predominant during the event, convection was embedded 339 within the stratiform precipitation. This is evidenced by Figure6, which shows the vertical-profile 340 sequence of UHF radar signals over the Argonne Weather Observatory, from 2013 April 172000 
341 UTC to April 181600 UTC. Lower left panel shows a picture of the UHF radar. The right top

342 plot gives pseudo-reflectivity profiles (expressed as the signal-to-noise ratio times the square of

343 the kilometer range, in decibels), and the right bottom plot gives profiles of the vertical Doppler

344 velocity (in $\mathrm{m} \mathrm{s}^{-1}$, positive downwards), both according to the corresponding color scales on the

345 right.The $\mathrm{y}$ axis corresponds to height in km above the ground level, and the $\mathrm{x}$ axis to UTC time.

346 Note several periods (e.g., 2013 April 180130 UTC at $4 \mathrm{~km}$ agl in bottom right panel)

347 characterized by updrafts (negative Doppler velocities in Fig.6), the bright band persistent

348 around $3 \mathrm{~km}$ agl (top right panel), and thevertical Doppler velocities (often below $2.5 \mathrm{~km}$

349 height)mostly between 6 and $10 \mathrm{~m} \mathrm{~s}^{-1}$. These Doppler magnitudes are typical fall velocities for

350 medium and large raindrops (corresponding to diameters larger than $1.7 \mathrm{~mm}$ in the measurements

351 by Gunn and Kinzer, 1949).All these suggest that the heavy-rain event studied was

352 predominantly liquid below $3 \mathrm{~km}$, according to the melting layer height detected by the UHF

353 wind profiler radar at Argonne. Therefore, thenext subsection will aim at comparing liquid

354 precipitation estimates between the numericalsimulations and the observations.

\section{3.2. Model validation}

356 For conciseness and structure, this subsection will present analyses only on the 357 observational and Best run (as per Table 1) datasets. A latersubsection (3.3. Model Sensitivity)

358 will extend on the results obtained with the other model parameterization experiments (Control 359 and Tests 1-3).

\subsubsection{Synoptic scale}

361 The WRF Best simulations effectively captured the synoptic features of the heavy-rain event. 362 Figure7a shows the simulations for 500-hPa geopotential heights at 0600 UTC 18 
363 April(simulation spin-up time equal to 2.5 days), which were consistent with corresponding

364 reanalysis fields of a low-pressure system at $110^{\circ}-105^{\circ} \mathrm{W}$ and $35^{\circ}-45^{\circ} \mathrm{N}$ (Fig.3a), along with a

365 ridge downstream of the trough near $80^{\circ} \mathrm{W}$. Such agreement is also evident for the sea level

366 pressure field (Figs. 3d and 7b), which shows a southwest-to-northeast trough, in the same

367 direction as the wind shear line at $850 \mathrm{hPa}$ (Figs. $3 \mathrm{~b}$ and7c). One can argue that this trough and

368 shear line together determined the position of the precipitation band in Fig. 2. At surface,

369 moisture convergence is expected along the cold front over the U.S. Midwest.At $850 \mathrm{hPa}$, the

370 low-level jet (Figs. 3b and7c) transported additionalmoisture from the Gulf of Mexico andthe

371 Midwest, and the cyclonic shear led to the convergence of moisture at the lower level. Moreover,

372 ascending motion over the area, with southerly flow stronger than over other areas (Fig.7c),

373 lifted the moisture at the lower level to the upper level and contributed to the generation of 374 precipitation.

375 Figure8presents integrated vapor transport (IVT) fields as simulated by the Best run (Table 376 1), which can be compared to the NCEP-FNL reanalysis fields in Fig.4. The model simulations

377 were able to capture the IVT spatial pattern coming from the Gulf of Mexico and proceeding to 378 the Midwest. From 1800 UTC April 17 to 1200 UTC April 18 (not shown), we noted that the 379 simulated IVT magnitudesincreased by $600-700 \mathrm{~kg} \mathrm{~m}^{-1} \mathrm{~s}^{-1}$ during the south-to-north movement 380 of the flow. One can argue that this increase corresponds to an important moisture resource for 381 the heavy precipitation that occurred over the Midwest.

\subsubsection{Mesoscale scale}

383 We analyze here daily precipitation datasets from NCDC rain gauge measurements to 384 evaluate WRF performance in 24-h accumulated precipitation. Figure9a identifies the stations 
385 with 24-h rainfall > $80 \mathrm{~mm}$ over Iowa, Illinois, and Missouri. The red dashed square corresponds

386 to the Chicago area, which ispresented enlarged in Fig.9b. Clustering of the stations in southern

387 Iowa, northern Illinois, and northern Missouri shows a southwest-to-northeast rainfall belt.

388 Totals of 81, 331, and 57 stations (out of 635, 715, and 565 available) across Iowa, Illinois, and

389 Missouri, respectively, recorded 24-h rainfall > $80 \mathrm{~mm}$ during 17-18 April 2013. Among these,

390 44, 205, and 24 stations across Iowa, Illinois, and Missouri, respectively, recorded 24-h rainfall >

$391 \quad 100 \mathrm{~mm}$.

392 Figures 10a-c compare NCDC observed and Best simulated 24-h accumulated rainfall over 393 the stations shown in Fig. 11a.The WRF model underestimatedextreme rainfall(> 80 mm)over $39477.8 \%, 73.1 \%$, and 71.9\% ofthe stations in Iowa, Illinois, and Missouri, respectively. Among 395 these, $43.2 \%, 3.0 \%$, and $10.5 \%$ of the stations over Iowa, Illinois, and Missouri, respectively,had 396 rainfall underestimated by more than 50\%.The RABvalues (as per Eq. 2) over Iowa, Illinois, and 397 Missouri (-32.1, -14.1, and $-16.6 \mathrm{~mm}$, respectively)indicate thatthe model performed slightly 398 better over Illinois than over the other two states.

399 Figure 11compares NWSRFC (2013) observed (Fig. 11a) and Bestsimulated (Fig. 11b) 24-h 400 accumulatedprecipitation over Domain d03.The WRF reproduced a southwest-to-northeast 401 precipitation belt thatwas narrower than the observation over Iowa and Illinois andthus resulted 402 in underestimation of precipitation around the area at $41.5^{\circ}-42.5^{\circ} \mathrm{N}$ and $91^{\circ}-89^{\circ} \mathrm{W}$. On the 403 other hand, the model generated areas of heavier precipitation around $40.5^{\circ}-41.5^{\circ} \mathrm{N}$ and $93^{\circ}-89^{\circ}$ 404 W, as well as south of Kansas City, Missouri. The spatial correlation coefficient between 405 observations and the Best simulation is 0.42 (Table 3). 
To complete the evaluation of the WRF model performance in the temporal variation of 407 precipitation over the entire Domain d03, Fig.12compares the NWS RFC (2013) observed and 408 the WRF modeled hourly precipitation during 0000-2100 UTC 18 April. According to the NWS 409 RFC (2013) observation (Fig.12a), the precipitation started over Iowa and northeastern Missouri 410 at 0000 UTC, moving eastward and arriving in Illinois at around 0300 UTC. Then the 411 precipitation veered to northeastern Illinois and achieved maximum rainfall around the Chicago 412 area at 0600-0900 UTC. After 0900 UTC, the position of precipitation belt changed from 413 southwest-to-northeast to south-to-north, moving to the southeast during 1500-2100 UTC.

414 The Best simulation (Fig.12a) captured the hourly evolution of precipitation to a certain 415 extent, but it showed varied bias during different periods. For example, at 0000-0300 UTC the 416 model overestimated the precipitation over the boundary between southwest Iowa and northwest 417 Illinois, which caused the overestimation of the 24-h accumulated precipitation shown in 418 Figs.10a-c and11b. At 0600-1500 UTC, the model underestimated the precipitation over 419 northern Illinois and southeast Iowa, leading to a narrower precipitation band than the 420 observation (Fig.11b).

421 To evaluate the simulation of precipitation diurnal variability during the flood event, Figure 422 13shows time series of the spatially-averaged precipitation for Domain d03 (Fig. 13a) and for the 423 Chicago area (Fig. 13b). These panels plot the NWS RFC observed (Obs., black lines) and Best 424 simulated (WSM-KF, red lines) precipitation values for 18 April 2013. We find a persistent bias 425 (underestimation some times larger than $1 \mathrm{~mm} \mathrm{~h}^{-1}$ ) in the Best simulations over Domain $\mathrm{d} 03$, as 426 well as a time lag (simulation is late by about 2 hours) in the Best simulations over the Chicago 427 area. 
429 Figure14presents the time evolution on profiles of horizontal wind over the Argonne Weather

430 Observatory during the flood event, according to observations by UHF wind profiler radar (top

431 left panel) and WRF simulations (other panels). The observations indicatethat the horizontal

432 flows during 0800-1200 were mostly from the west and southwest. In the WRF Best simulation,

433 however, the southerly flow was weaker, and some flows were from the north and northwest

434 around 1000 UTC and later on 18 April.

435 Figure15presents time series ofprecipitation intensityat the Argonne Weather Observatory

436 during the flood event, as measured by the Parsivel2 sensor and as simulatedby the WRF model

437 (according to the parameterizations in Table 1). While the observations correspond to average

438 rainratesover 1-minute periods, the simulated rainfall rates are obtained fromtotal rainfall

439 accumulations within10-minutes periods. Therefore, to match and quantitatively compare these

440 datasets using Eq. 3, we had to first accumulate the 1-min rainrate observations to 10-min

441 periods, then find the 10-min observation value that is closest in time to each particular 10-min

442 simulation value, and finally assume that the representativeness of the 10-minsimulation value is

443 very close to the representativeness of the 10-min observation value.

444 With these considerations, we computed site percent biases (for the 24-h accumulated 445 precipitation from 1200 UTC 17 April to 1200 UTC 18 April 2013.Focusing here on the right 446 top plot, we find that the Best simulation reproduced the rainfall at Argonne very well, with only $4473.65 \%$ underestimation in comparison with the observation. This allows further investigation of 448 the model performance in short-periodtemporal evolution. The Bestsimulationperformed well 449 from 2200 UTC 17 April to 0200 UTC 18 April and from 0800 UTC 18 April to 1200 UTC 18 
450 April, and captured the occurrence of heavy rain during these periods, with the heaviest 451 precipitation intensity $40 \mathrm{~mm} \mathrm{~h}^{-1}$. However, the model missed the rain during 0400-0800 UTC 45218 April and during 1200-1600 UTC 18 April, causing model underestimation of the 453 meanrainfall intensity during the selected period $-3.35 \mathrm{~mm} \mathrm{~h}^{-1}$, weaker than the Parsivel2 454 observation $\left(5.11 \mathrm{~mm} \mathrm{~h}^{-1}\right)$.

\subsection{Model Sensitivity}

456 Sensitivity experiments designed to investigate the possible causes of the deficiencies in the 457 microphysics and cumulus parameterizations are discussed in the following subsections.

\section{$458 \quad$ 3.3.1.Sensitivity to microphysics}

459 Figures 10d-f compare the simulated 24-haccumulated rainfall by Test 1 (Morr-KF)and Test

4602 (WDM-KF) over the observatories across the three states. Over Iowa (Fig. 10d),Test 1 461 performed better than Best (WSM-KF, Fig. 10a), because Test 1 (Morr-KF)reduced the RAB 462 from $-32.1 \mathrm{~mm}$ to $-15.6 \mathrm{~mm}$. In contrast, over the stations in Illinois (Fig. 10e) and Missouri 463 (Fig. 10f), Test 1 (Morr-KF, Figs. 10e-f) performed more poorly than did Best (WSM-KF, Figs. $46410 \mathrm{~b}-\mathrm{c})$, showing more underestimation of rainfall:-25.5 and $-23.6 \mathrm{~mm}$ by Test 1 versus -14.1 and $465-16.6 \mathrm{~mm}$ by Best, respectively.Test 2 (WDM-KF)performed more poorly than Best (WSM-KF) 466 and Test 1 (Morr-KF), showingunderestimation of rainfall over $92.6 \%$ and $97.3 \%$ of the stations, 467 respectively, and underestimated the rainfall by more than $50 \%$ for $49.4 \%$ and $29.9 \%$ of the 468 stations in Iowa and Illinois, respectively. The RABvalues were -43.7 and $-45.8 \mathrm{~mm}$ over Iowa 469 and Illinois, respectively (Figs. 10d-e). However, Test 2 (WDM-KF) reduced the bias over 470 Missouri from the Best (WSM-KF) value of $-16.6 \mathrm{~mm}$ (Fig. 10c) to $-9.1 \mathrm{~mm}$ (Fig. 10f). 
Regarding the simulation skill as a function of the spin-up time, Table 4 presents the regional

472 average bias (RAB, in $\mathrm{mm}$ ) for different spin-up times (in hours). In these cases, we find no

473 systematic pattern between the integration times and the RAB values. However, the RAB

474 ensemble mean (bottom row) is similar or much smaller than the RAB ensemble mean of

475 corresponding values in Fig. 10 (-30.96 mm for IA, -41.60 mm for IL, and -28.32 mm for MO).

476 In other words, the impacts on model bias due to changes the initial conditions (model internal

477 variability) is mostly smaller than those due to changes in parameterizations (model

478 parameterization variability). It is a desired feature that our model exhibits internal variability

479 smaller than parameterization variability.

480 Figures11c-d show the simulated 24-h accumulated precipitation by Morr-KF (Test 1) and 481 WDM-KF (Test 2) over Domain d03. Improvements and differences can be found between 482 WSM-KF (Best)and these two sensitivity experiments. The precipitation overestimatesin 483 southeastern Iowa, northwestern Illinois, and Kansas City, Missouri, were all reduced by Morr484 KF. Moreover, Morr-KF (Test 1) generated a broader precipitation band than did WSM-KF 485 (Best), closer to the observation. WDM-KF (Test 2) solved the overestimation problem but 486 generated much lighter precipitation than the observation over northern Illinois. Therefore, the 487 Morrison microphysics with KF cumulus parameterization showed improvements over WSM6 488 and WDM6 in the 24-h accumulated precipitation of this heavy-rain eventin terms of spatial 489 patterns. The spatial correlation between the observation and the Morr-KF (Test 1) simulation 490 was 0.45, while that between the observation and the WDM-KF (Test 2)simulation was 0.34.

As Fig. 12b (left two) shows, Morr-KF (Test 1) produced a precipitation spatio-temporal 492 pattern similar to that of WSM-KF (Best, Fig. 12a), but Morr-KF (Test 1) reduced the 493 overestimation of precipitation during 0000-0900 UTC 18 April and during 1200-2100UTC 18 
494 April over the boundary between southeastern Iowa, northwestern Illinois, and northeastern 495 Missouri.Moreover, Morr-KF (Test 1) generated heavier rainfall over northern Illinois than did 496 WSM-KF (Best). These features generated by Morr-KF (Test 1) are closer to the observation 497 than those resulting from WSM-KF (Best). WDM-KF (Test 2, Fig. 12b, third and fourth 498 columns)produced too little precipitation over northern Illinois, especially near the Chicago area.

To quantify and compare performances of the three microphysics schemes (WSM6, 500 Morrison, and WDM6) at the regional scales, Table 2 shows 24-h accumulated precipitation 501 averaged for Domain d03 (Fig. 1bottom) and for the Chicago area (Fig. 9b), from the NWSRFC 502 (2013) observations and correspondingmodel simulations. WSM-KF (Best) outperformed Morr$503 \mathrm{KF}$ (Test 1) and WDM-KF (Test 2), showing a precipitation of $45.3 \mathrm{~mm}(79.5 \mathrm{~mm})$ versus 43.6 $504 \mathrm{~mm}(69.8 \mathrm{~mm})$ and $42.9 \mathrm{~mm}(50.9 \mathrm{~mm})$, closer to the observational value over Domain $\mathrm{d} 03$ 505 (Chicago area). In addition, when comparing the three-state average bias for 24-h accumulated 506 rainfall(on NCDC stations with values $>80 \mathrm{~mm}$, as shown by the numbers at the top of the plots 507 in Fig. 10),one finds that WSM-KF (Best) also performed betterthanTest 1 and Test 2, showing 508 bias of $-20.9 \mathrm{~mm}$ versus -21.6 and $-32.9 \mathrm{~mm}$. Since the WSM-KF parameterization generated the 509 closest agreement with these NWS RFC and NCDC observational datasets, we decided to name 510 it Best.

511 Regarding the diurnal variability of precipitation, Figure 13a indicates that allof the 512 simulations underestimated the precipitation (a bias) over Domain d03, and thatWSM-KF (Best) 513 and Morr-KF (Test 1) performedcloser to the observation than WDM-KF (Test 2) during the 24 514 h. Over the Chicago area (Fig. 13b), all of the models produced rainfall peaks $2-3 \mathrm{~h}$ later than 515 the observation (a time lag), which peaked at around 0600 UTC. The rainfall peak by WSM-KF 516 (Best) was $1 \mathrm{~h}$ closer to the observation than the Morr-KF (Test 1) and WDM-KF(Test 2) peaks. 
517 At the Argonne site, Figure15indicates that the Morr-KF (Test 1) simulation showed longer 518 duration of rainfall than WSM-KF (Best) from 2000 UTC 17 April to 0000 UTC 18 April, as 519 well as during 1300-1600 UTC 18 April. However, Morr-KF (Test 1) missed the rainfall during 520 0000-0800 UTC 18 April, and it underestimated the 24-h precipitation by $17.1 \%$. WDM-KF 521 (Test 2) generated much lighter rainfall during the whole period than both WSM-KF (Best) and 522 the Parsivel2 observation, which resulted in underestimation of 24-h accumulated rainfall by

$52333.3 \%$. The mean rainfall intensities during the selected period simulated by Test 1 and Test 2

524 were much weaker than the intensity for the Best simulation (2.94 and $1.74 \mathrm{~mm} \mathrm{~h}^{-1}$ versus 3.35 $525 \mathrm{~mm} \mathrm{~h}^{-1}$, respectively).

\subsubsection{Sensitivity to cumulus parameterizations}

527 Figures 10g-ishow the 24-h accumulated rainfall simulated by WSM-GD(Test 3) and Morr$528 \mathrm{GD}(\mathrm{Control})$ over stations across the three states.As shown by the RAB values in Fig. 10g-i, 529 both WSM-GD and Morr-GD significantly underestimated the rainfall,by 35.6-66.5\%,over more 530 than $80 \%$ of the stations in Iowa, Illinois, and Missouri.

531 As Figs. 11e-f show, WSM6 and Morrison microphysics with the GD cumulus 532 parameterization performed differently in producing precipitation at different locations over 533 Domain d03. In comparison with WSM-KF(Best) simulation, both WSM-GD (Test 3) and Morr534 GD (Control) decreased the overestimation of precipitation over the boundary between Iowa, 535 Missouri, and Illinois, as well as that over Kansas City, Missouri. However, WSM-GD (Test 3) 536 generated much lighter precipitation than the observation during the $24 \mathrm{~h}$ over Domaind03 (as 537 shown in Table 2 and stated below). Morr-GD (Control)generated slightly heavier precipitation 
538 than WSM-GD (Test 3), but it still showed significant dry bias over northeastern Missouri and 539 Illinois.

540 In the WSM-GD experiment (Test 3, Fig. 12c, two first columns on the left), the 541 simulationsdid not produce enough precipitation over western Iowa at 0000 UTC and over 542 northern Illinois at 0300-1200 UTC. Theresult was significant underestimation of precipitation 543 over Domain d03 (as shown by Table 2 and stated below). Very light precipitation near the 544 Chicago area was simulated during the $24 \mathrm{~h}$ by Morr-GD (Control, Fig. 12c, third and fourth 545 columns on the right), with only 4-6 mm precipitation at 1500 UTC 18 April.

546 Table 2quantifies the difference in the performances of the two cumulus parameterizations 547 (KF and GD) in 24-h accumulated precipitation at a regional average scale. Generally, the GD 548 cumulus parameterization underestimated precipitation more significantly than did the KF over 549 both Domain d03 and the Chicago area, and showed large dry bias for both microphysical 550 schemes tested in this study (WSM6 and Morrison). As the numbers at the top of Figs. 10g-i 551 indicate for the three-state average bias, WSM-GD (Test 3) and Morr-GD (Control) 552 underestimated the 24-h accumulated precipitation (on sites with values $>80 \mathrm{~mm}$ ) by 52.1 and $55340.7 \mathrm{~mm}$. In addition, the simulations with the GD cumulus parameterization underestimated the 554 diurnal evolution of precipitation over Domain d03 (Fig. 13a)the Chicago area (Fig. 13b).Both 555 WSM-GD (Test 3) and Morr-GD (Control) produced rainfall peaks 2-3 $\mathrm{h}$ later than the 556 observation, which peaked at around 0600 UTC. WSM-GD (Test 3) generated a second peak at 557 around 1400UTC that did not exist in the observation.

558 Regarding the 10-min precipitation intensity at the Argonne site, the simulations by WSM559 GD (Test 3) and Morr-GD (Control) experiments were much lighter than the observations (Fig. 
560 15). The observations temporal evolution was different from that of WSM-KF (Best), as well as

561 Morr-KF (Test 1) and WDM-KF (Test 2). No rain or very light rain generated before 0900 UTC

56218 April resulted in underestimations of $24-\mathrm{h}$ accumulated rainfall by $53.2 \%$ and $73.9 \%$ by

563 WSM-GD (Test 3) and Morr-GD (Control), respectively. The mean rainfall intensities for the

564 Test 3 and Control runs were only 1.91 and $1.56 \mathrm{~mm} \mathrm{~h}^{-1}$, much weaker than the observation

$565\left(5.11 \mathrm{~mm} \mathrm{~h}^{-1}\right)$ and Best simulation $\left(3.35 \mathrm{~mm} \mathrm{~h}^{-1}\right)$.

566 One may wonder if close-by areas of the simulation grid may have reproduced better the

567 observed precipitation pattern. In other words, if the simulations just missed the correct location.

568 To investigate this, Table 5 presents the Site Percent Bias at the nine simulation points closest to

569 the Argonne site. Some parameterization configurations have its minimum SPB value at grid

570 points other than the closest (i.e., missed the correct location on average). However, we note that

571 the BEST parameterization configuration is giving the desired result that SPB is smaller at the

572 closest grid point.

\section{4. Discussion}

574 Weinvestigate here possible reasons for the model bias in precipitation, and use the 575 simulation results to understand moisture sources and dynamic features of the atmosphere during 576 the flood event. For this, vertical profiles of rain water mixing ratio, water vapor mixing ratio, 577 vertical velocity, and horizontal wind fields were compared among the five simulations and were 578 evaluated by using measurementsfrom the ArgonneWeather Observatory.

579 Figure 16shows the time-height cross section of rain water mixing ratio in the five 580 simulations. The values correspond to domain d03 outputs, which provides one profile every 10 581 minutes.Thedistributionsare very similar to the simulated precipitation(Fig. 15). For example, 
582 Morr-KF(Test 1) showeda stronger rain water mixing ratio during 2000 UTC 17 April to 0000

583 UTC 18 April than the other four simulations (Fig. 16), and Morr-KF (Test 1) produced the

584 heaviest rainfall during this period (Fig. 15). WSM-GD(Test 3) and Morr-GD(Control) showed

585 very small or no rain water before 0800 UTC 18 April (Fig. 16), and very light rainfall occurred 586 during this period (Fig. 15).

What is the source of the rain water and what are the conditions that created the event? To

588 answer this question, the water vapor mixing ratio, vertical velocity, and horizontal winds were 589 investigated.Figure 17 presents time-height cross sections of water vapor mixing ratio (left, $\mathrm{g} \mathrm{kg}$ 590 1) and ascending motion (right, $\mathrm{m} \mathrm{s}-1$ ) for the five simulations in Table 1 . The simulations 591 exhibit similar moisture patterns before and during the sharp frontal transition, around 0900 UTC 592 (Fig. 17, left). This sharp transition is also present if we reproduce the time-height cross sections 593 in Fig. 17 for the 6km-by-6km area around the point near Argonne site (not shown). This 594 indicates that the sharp transition is not a phenomena of only one pixel. When one considers that 595 the simulations also have subtle low-level wind differences during the frontal passage (Fig. 14), 596 we remain challenged to physically relate these similarities to the very different precipitation 597 patterns during the period (Fig. 16).

598 As Fig. 17(left) shows, water vapor concentrated very strongly around 0400-0800 UTC 18 599 April below 3km in WSM-KF (Best),Morr-KF (Test 1), and WDM-KF (Test 2), setting thestage 600 for the precipitation occurring around 0800-1200 UTC. WSM-GD (Test 3) and Morr-GD 601 (Control) showed stronger water vapor abundances before 0400 UTC 18 April than the other 602 three experiments, because WSM-GD (Test 3)and Morr-GD(Control) generated continuous and 603 stronger southerly flow (Fig. 14) during 0000-0400 UTC 18 April than the other three 604 experiments (and the observation). The southerly flow originated over the Gulf of Mexico and 
transported warm, moist water vapor to theMidwest (Figs. 3b and 7c). However, since very weak

606 ascending motion (Fig. 17right, Test 3 and Test 4) occurred during this period, no rain or very

607 light rain was observedduring 0400-0800 UTC 18 April (Fig. 15) from this available moisture.

608 No rain was generated during 0400-0800 UTC 18 April by WSM-KF (Best), Morr-KF (Test 1),

609 or WDM-KF (Test 2), as per Fig. 15and Fig. 16, because ofthe smaller water vapor before 0400

610 UTC 18 April (Fig. 17left). That is, smallerthan the water vapor profiles by WSM-GD(Test 3)

611 and Morr-GD(Control). There were intermittent ascending motions(Fig. 17right), though.Later,

612 the water vapor amount increased substantially because of southerly flow and was supported by

613 ascending motions during 0400-0800 UTC 18 April, setting the stage for the formation of

614 precipitation during 0800-1200 UTC April 18.On the other hand, and as noted earlier, the UHF

615 observed horizontal flows (Fig.14top left panel) during 0800-1200 were mostly from the west

616 and southwest. For all the WRF simulations in Fig. 14, the southerly flow was very weak, and

617 some flows were from the northand northwest around 1000 UTC and later on 18 April. This led

618 to a sharp decrease in water vapor (Fig. 17left) at this timeperiod in the model simulations.

619 Although there were strong ascending motions in the other four simulations (Fig. 17right), they

620 were not moist enough to generate precipitation as heavy as in WSM-GD (Test 3), which

621 effectively captured the strong southerly flowand transported the moisture from south to the

622 north (Fig. 14). As Fig. 17(left) shows, WSM-GD (Test 3) simulated the mostwater vapor during

$623 \quad 0900-1400$ UTC below 3km at Argonne.

\section{5. Conclusions}

625 The 2013 Chicago Spring Floods are associated here to an atmospheric river of extreme 626 intensity, which is above the maximum level in the 1979-2011 climatology for April over the 627 Central United States (Lavers and Villarini, 2013b). The event corresponds to a golden case for 
628 testing numerical weather prediction techniques that could fill our understanding gaps on high-

629 impact floods, for whichcomprehensive observation datasetsare limited. This study attempted to

630 reproduce the heavy rainfall observations by using numerical simulations from the Advanced

631 Research WRFmodel at a high spatial resolution $(3 \mathrm{~km})$, using nested domains and spectral

632 nudging. The model performance was evaluated for the synopticscale, mesoscale, and local

633 scaleby using a comprehensive set of observational datasets gathered at Argonne National

634 Laboratory and across Illinois, Iowa, and Missouri.

635 A control simulation with WSM6, KF, and other physical schemes was set up to reproduce

636 the atmospheric circulation and the spatio-temporal pattern of the heavy-rain event.Four

637 supplementary sensitivity experiments with different microphysics schemes and cumulus

638 parameterizationswere designed to investigate the possible reasons for the model bias. Vertical

639 profiles of rain water, water vapor mixing ratio, ascending motion, and horizontal winds were

640 also evaluated and compared. Our major findings are summarized as follows:

641 - All of the simulations captured the synoptic-scale features of atmospheric circulation, but 642 they generated different biases with different microphysics and cumulus 643 parameterizations in 24-h accumulated precipitation and minute-scale temporal $644 \quad$ evolutions.

645 - All of the simulations underestimated the 24-h accumulated precipitation and the diurnal 646 variations of precipitation over Domain $\mathrm{d} 03$ and the Chicago area, and they 647 generatedrainfall peakslagging the observed peaks by $2-3 \mathrm{~h}$.

648 - Among the five simulations, WSM-KF (Best) and Morr-KF (Test 1) outperformed the 649 others in regionally averaged 24-h accumulated precipitation and diurnal variations. 650 Morr-KF (Test 1) performed better than WSM-KF (Best) in capturing the spatial patterns 
of 24-h accumulated precipitation.

672 and it could not capture the short-period temporal variation of rainfall; it generated much lighter

673 rainfall than the control simulation and the observations and is not discussed here. 
There is a plethora of other possible sensitivity experiments that we did not present here. For

675 example would be to test sensitivity of the results on the initial conditions (e.g., initializing the

676 model with FNL data at 00 UTC on April 16 instead of 12 UTC on April 15). The Domain d03

677 seems to be very sensitive to the choice of convection scheme in outer domains, as demonstrated

678 by the large difference between simulations with different cumulus parameterizations in the

679 manuscript. One may also want to test different parameterizations for the Planetary Boundary

680 Layerdynamics, radiation schemes, and land surface schemes.

681 In conclusion, the integration of data from Argonne's radar and simulation platforms near a

682 large city (Chicago) during a high-impact weather event has opened new doors for developing

683 useful precipitation and hydrologic modeling applications in the urban context.

Acknowledgements. This work was supported under U.S. Department of Energy (DOE) Contract DE-AC02-06CH11357.The numerical simulations were performed on the DOE687 supported supercomputing clusters of the National Energy Research Scientific Computing Center 688 and the Argonne Leadership Computing Facility. The authors thankDr. Scott Collis and Dr. 689 Jonathan Helmusof Argonne National Laboratory for providing Figures 5and 2(respectively).

690 The submitted manuscript has been created by UChicago Argonne, LLC, Operator of 691 Argonne National Laboratory (“Argonne”). Argonne, a U.S. Department of Energy Office of 692 Science laboratory, is operated under Contract No. DE-AC02-06CH11357. The U.S. 693 Government retains for itself, and others acting on its behalf, a paid-up nonexclusive, irrevocable 694 worldwide license in said article to reproduce, prepare derivative works, distribute copies to the 695 public, and perform publicly and display publicly, by or on behalf of the Government. 


\section{References:}

697 Campos, E., 2013: The Argonne weather observatory website (http://weather.anl.gov). Accessed 15 April 2015.

Chen, F., and J. Dudhia, 2001: Coupling an advanced land surface hydrology model with the Penn State-NCAR MM5 modeling system. Part I: Model implementation and sensitivity. Mon. Wea. Rev., 129, 569-585.

Collis, S., W.-K. Tao, S. Giangrande, A. Fridlind, A. Theisen, and M. Jensen, 2013:Quantitative rainfall metrics for comparing volumetric rainfall retrievals to fine scale models. EGU General Assembly 2013, held 7-12 April, 2013 in Vienna, Austria, id. EGU2013-3576.

Dee, D. P., Uppala, S. M., Simmons, A. J., Berrisford, P., Poli, P., Kobayashi, S., Andrae, U., Balmaseda, M. A., Balsamo, G., Bauer, P., Bechtold, P., Beljaars, A. C. M., van de Berg, L., Bidlot, J., Bormann, N., Delsol, C., Dragani, R., Fuentes, M., Geer, A. J., Haimberger, L., Healy, S. B., Hersbach, H., Hólm, E. V., Isaksen, L., Kållberg, P., Köhler, M., Matricardi, M., McNally, A. P., Monge-Sanz, B. M., Morcrette, J.-J., Park, B.-K., Peubey, C., de Rosnay, P., Tavolato, C., Thépaut, J.-N. and Vitart, F. (2011), The ERAInterim reanalysis: configuration and performance of the data assimilation system. Q.J.R.

713 Fowler, L. D., and D. A. Randall, 2002: Interactions between cloud microphysics and cumulus 714 convection in a general circulation model. J. Atmos. Sci., 59, 3074-3098. 
715 Gallus, W. A., and J. F. Bresch, 2006: Comparison of Impacts of WRF Dynamic Core, Physics 716 Package, and Initial Conditions on Warm Season Rainfall Forecasts. Mon. Wea. Rev., 134, 2632-2641. doi: http://dx.doi.org/10.1175/MWR3198.1.

718 Gao, Y., J. S. Fu, J. B. Drake, Y. Liu, and J.-F. Lamarque, 2012: Projected changes of extreme 719 weather events in the eastern United States based on a high resolution climate modeling system. Environ. Res. Lett.,7044025.doi:10.1088/1748-9326/7/4/044025.

721 Grell, G. A., and D. Dévényi, 2002: A generalized approach to parameterizing convection 722 723

Hong, S.-Y., J. Dudhia, and S. H. Chen, 2004: A revised approach to ice microphysical processes for the bulk parameterization of clouds and precipitation. Mon. Wea. Rev.,132, 103-120.

728 Hong, S.-Y., K.-S. Lim, Y.-H. Lee, J.-C. Ha, H.-W. Kim, S.-J. Ham, and J. Dudhia, 2010: Evaluation of the WRF double-moment 6-classmicrophysics scheme for precipitating convection. Advances in Meteorology, doi:10.1155/2010/707253.

731 Iacono, M. J., J. S. Delamere, E. J. Mlawer, M. W. Shephard, S. A. Clough, and W. D. Collins, 732 2008: Radiative forcing by long-lived greenhouse gases: Calculations with the AER radiative transfer models.J. Geophys. Res., 113, D13103, doi:10.1029/2008JD009944. 
734 Jaffrain, J., and A. Berne, 2011: Experimental quantification of the sampling uncertainty 735 associated with measurements from PARSIVEL disdrometers. J. Hydrometeor, 12, 352736 370. doi: http://dx.doi.org/10.1175/2010JHM1244.1.

737 James, K. A., D. J. Stensrud, and N. Yussouf, 2009: Value of real-time vegetation fraction to 738 forecasts of severe convection in highresolution models. Wea. Forecasting, 24,187-210.

739 Kain, J. S., 2004: The Kain-Fritsch convective parameterization: An update. J. Appl. Meteor., $740 \quad 43,170-181$.

741 Kain, J. S., and J. M. Fritsch, 1990: A one-dimensional entraining/detraining plume model and 742 its application in convective parameterization. J. Atmos. Sci., 47, 2784-2802.

743 Kain, J. S., and J. M. Fritsch, 1993: Convective parameterization for mesoscale models: The Kain-Fritsch scheme. The representation of cumulus convection in numerical models.Meteor. Monogr., 24, 165-170.

746 Kuligowski, R. J., 1997: An overview of national weather service quantitative precipitation estimates. National Oceanic and Atmospheric Administration, National Weather Service, Office of Systems Development Techniques Development Laboratory. 2005 heavy rain event over Mumbai, India using the Weather Research and Forecasting (WRF) model. Q.J.R. Meteorol. Soc.,134: 1897-1910. doi: 10.1002/qj.325. 
752 Kunkel, K. E., K. Andsager, and D. R. Easterling, 1999: Long-term trends in extreme 753 precipitation events over the conterminous United States and Canada. J. Climate, 12, 754

Kunkel, K. E., D. R. Easterling, K. Redmond, and K. Hubbard, 2003: Temporal variations of extreme precipitation events in the United States: 1895-2000. Geophys. Res. Lett., 30,

Kunkel, K. E., T. R. Karl, H. Brooks, J. Kossin, J. Lawrimore, D. Arndt, L. Bosart, D.

Lavers, D. A., and G. Villarini,2013: The nexus between atmospheric rivers and extreme precipitation across Europe.Geophys. Res. Lett., 40, 3259-3264, doi:10.1002/grl.50636.

Lavers, D. A., and G. Villarini,2013b: Atmospheric Rivers and Flooding over the Central United States. Journal of Climate, 26, 7829-7836, doi: 10.1175/JCLI-D-13-00212.1.

Leung, L. R., and Y. Qian, 2009: Atmospheric rivers induced heavy precipitation and flooding in the western U.S. simulated by the WRF regional climate model.Geophys. Res. Lett., 36, L03820, doi:10.1029/2008GL036445. processes and heavy rainfall in urban environments: Sensitivity to urban surface representations. J. Hydrometeor, 14, 1098-1118. doi: http://dx.doi.org/10.1175/JHM-D12-0154.1. 
$773 \mathrm{Li}, \mathrm{X}$., and Z. Pu, 2008: Sensitivity of numerical simulation of early rapid intensification of 774 Hurricane Emily (2005) to cloud microphysical and planetary boundary layer parameterizations.Mon. Wea. Rev.,136, 4819-4838.

776 Lim, K.-S., and S.-Y. Hong, 2010:Development of an effective double-moment cloud 777 microphysics scheme with prognostic cloud condensation nuclei $(\mathrm{CCN})$ for weather and climate models.Mon. Wea. Rev.,138, 1587-1612.

779 Liu, C., K. Ikeda, G. Thompson, R. Rasmussen, and J. Dudhia, 2011: High-resolution 780

Miguez-Macho, G., G. L. Stenchikov, and A. Robock, 2004: Spectral nudging to eliminate the simulations of wintertime precipitation in the Colorado headwaters region: Sensitivity to physics parameterizations. Mon. Wea. Rev., 139, 3533-3553. doi: http://dx.doi.org/10.1175/MWR-D-11-00009.1.

Miguez-Macho, G., G. L. Stenchikov, and A. Robock, 2005: Regional climate simulations over North America: Interaction of local processes with improved large-scale flow. J. Climate, effects of domain position and geometry in regional climate model simulations. $J$. Geophys. Res., 109, D13104, doi:10.1029/2003JD004495. 18, 1227-1246.

Molthan, A. L., 2011: Evaluating the performance of single and double moment microphysics schemes during a synoptic-scale snowfall event. $24^{\text {th }} / 20^{\text {th }}$ AMS Conferences on Weather and Forecasting/Numerical Weather Prediction, Seattle, WA, 2011.

792 Morrison, H., G. Thompson, and V. Tatarskii, 2009: Impact of Cloud Microphysics on the 793 Development of Trailing Stratiform Precipitation in a Simulated Squall Line: Comparison 
of One- and Two-Moment Schemes. Mon. Wea. Rev.,137, 991-1007. doi: http://dx.doi.org/10.1175/2008MWR2556.1.

796 National Centers for Environmental Prediction/National Weather Service/NOAA/U.S. Department of Commerce, 2000: NCEP FNL Operational Model Global Tropospheric Analyses, continuing from July 1999. Research Data Archive at the National Center for Atmospheric Research, Computational and Information Systems Laboratory, Boulder, CO. [Available online at http://dx.doi.org/10.5065/D6M043C6.] Accessed 5 September

Neiman, P. J., F. M. Ralph, G. A. Wick, J. D. Lundquist, and M. D. Dettinger, 2008: Meteorological characteristics and overland precipitation impacts of atmospheric rivers affecting the West Coast of North America based on eight years of SSM/I satellite observations. J. Hydrometeor, 9, 22-47. doi: http://dx.doi.org/10.1175/2007JHM855.1.

Noh, Y., W. G. Cheon, S.-Y. Hong, and S. Raasch, 2003: Improvement of the K-profile model 2013.

809 NWS, for the planetary boundary layer based on large eddy simulation data.Boundary Layer Meteorol., 107, 401-427. 2013(http://www.crh.noaa.gov/ilx/?n=apr2013flooding).

811 NWS RFC, 2013:National Weather Service River Forecast Centers Datasets (http://www.srh.noaa.gov/ridge2/Precip/qpehourlyshape/).

813 OTT, 2012: OTT operating instructions: Present weather sensor OTT Parsivel2. Document number 70.210.001.B.E. 04-0911. OTT Hydromet GmbH, 46 pp. 
815 Powers, J. G., 2007: Numerical prediction of an Antarctic severe wind event with the Weather

816 Research and Forecasting (WRF) model.Mon. Wea. Rev, 135, 3134-3157.

817 Py-ART, 2014: Python-ARM Radar Toolkit. GitHub, available at https://github.com/ARM-

$818 \quad$ DOE/pyart .

819 Rajeevan, M.,A. Kesarkar, S. B. Thampi, T. N. Rao, B. Radhakrishna, and M. Rajasekhar, 820 2010:Sensitivity of WRF cloud microphysics to simulations of a severe thunderstorm 821 event over Southeast India. Ann. Geophys., 28, 603-619.

822 RRTM, 2013: Atmospheric \& Environmental Research (AER) 823 Radiative Transfer Working Group Website. Available at http://rtweb.aer.com/ .

824 Shin, H., and S.-Y. Hong, 2009: Quantitative precipitation forecast experiments of heavy rainfall over Jeju Island on 14-16 September 2007 using the WRF model.Asia-Pacific Journal of Atmospheric Sciences, 45, 71-89.

827 Taylor, Z. R., 2011: The impact of cumulus parameterization schemes on the convective 828 829 transport of biomass burning emissions using WRF-CHEM. Masters thesis, The Florida State University. 7-9 pp.

830 Thompson, G., R. M. Rasmussen,and K. Manning, 2004: Explicit Forecasts of Winter 831 Precipitation Using an Improved Bulk Microphysics Scheme. Part I: Description and 832 Sensitivity Analysis. Mon. Wea. Rev.,132, 519-542. doi: http://dx.doi.org/10.1175/1520$833 \quad$ 0493(2004)132<0519:EFOWPU>2.0.CO;2. 
834 Thompson, G., P. R. Field, R. M. Rasmussen, and W. D. Hall, 2008: Explicit Forecasts of Winter 835 Precipitation Using an Improved Bulk Microphysics Scheme. Part II: Implementation of 836 a New Snow Parameterization. Mon. Wea. Rev.,136, 5095-5115. doi: $837 \quad$ http://dx.doi.org/10.1175/2008MWR2387.1.

838 Tripathi O. P., and F. Dominguez, 2013: Effects of spatial resolution in the simulation of daily 839 and subdaily precipitation in the southwestern US. J. Geophys. Res.,118, 7591-7605.

840 TRMM, 2014: Tropical Rainfall Measuring Mission website. National Aeronautics and Space 841 Administration. Available at http://pmm.nasa.gov/TRMM.

842 Vaisala, 2002a: Wind Profiling: History, Principles, and Applications. Technical Note, $843 \quad$ September 2002, 60 pp.

844 Vaisala, 2002b: Lower Atmosphere Profiler LAP®-3000: User's Guide. M210301en-A, PN 84580018001 Rev E, August 2002, 306 pp.

846 Wang, J., and V. R. Kotamarthi, 2013: Assessment of dynamical downscaling in near-surface fields with different spectral nudging approaches using the Nested Regional Climate Model (NRCM). J. Appl. Meteor. Climatol.,52, 1576-1591. doi: http://dx.doi.org/10.1175/JAMC-D-12-0302.1.

850 Wuebbles, D., G. Meehl, K. Hayhoe, T. R. Karl, K. Kunkel, B. Santer, M. Wehner, B. Colle, E. 851 M. Fischer, R. Fu, and co-authors, 2013: CMIP5 climate model analyses: Climate 852 extremes in the United States. Bullet. Amer. Meteorol. Soc., in press. doi: 853 http://dx.doi.org/10.1175/BAMS-D-12-00172.1. 
854 WSJ, 2013: Water damage company compares 5 worst floods in Chicago history.The WallStreet 855 Journal (http://online.wsj.com/article/PR-CO-20130423-905939.html). 


\section{Table and figure captions:}

857 TABLE 1. The microphysics schemes and cumulus parameterizations used for the five WRF 858 simulations in this study.

859 TABLE 2. Observed and simulated 24-h accumulated precipitation (in $\mathrm{mm}$ ) averagedover Domain d03 (Fig. 9a) and Chicago area (Fig. 9b).

861 TABLE 3. Spatial correlations between observations and the five WRF simulations in Figure 11.

862 TABLE 4. Regional average bias (RAB, as per Eq.2) over Iowa (IA), Illinois (IL), and Missouri (MO), for different spin-up times, and using the BEST model parameterization. All RAB values are calculated using the same 24h period, from April 1712 UTC to April 1812 UTC, 2013. The last row corresponds to the mean RAB value for all initial times except the $4^{\text {th }}$ row (the initialization time used in Fig. 10, in bold).

TABLE5. Site percent bias (SPB, as per Eq.3) for the model parameterizations in Table 1, at the nine simulation points closest to the Argonne site. The first column corresponds to the SPB values in Fig. 15.

871 FIG. 1.Temporal (top) and spatial (bottom) configuration of three WRF nested domains, d01, d02, and d03, using FNL reanalysis as initial and boundary conditions for the d01 domain. 
874 FIG. 2. 24-h accumulatedprecipitation data (mm) from 1200 UTC 17 April to 1200 UTC 18 April

875

876

877

878

879

880

881

882

883

884

885

886

887

888

889

890

891

892 (NWSRFC 2013). Image courtesy of Dr. Jonathan Helmus (Argonne National Laboratory).

FIG. 3. NCEP-FNL reanalysis data valid at 0600 UTC 18 April 2013, showing (a) $500 \mathrm{hPa}$ geopotential height and anomalies (m); (b) $850 \mathrm{hPa}$ winds and v-wind anomalies $\left(\mathrm{m} \mathrm{s}^{-1}\right)$; (c) precipitable water and anomalies (mm); (d) sea level pressure and anomalies (hPa).Magnitudes are plotted as black isolines or wind barbs, and April-2013 anomalies are plotted as color shades.

FIG. 4. Integrated vapor transport $\left(\mathrm{kg} \mathrm{m}^{-1} \mathrm{~s}^{-1}\right.$, from1000 to $\left.300 \mathrm{hPa}\right)$ at $0600 \mathrm{UTC}$ (top) and 1200 UTC (bottom) on 18 April 2013.Data from NCEP-FNL reanalysis.

FIG. 5. Field of equivalent reflectivityfactor over the Chicago region.Data from NEXRAD WSR88D radars. Image courtesy of Dr. Scott Collis (Argonne National Laboratory).

FIG. 6. The UHF radar wind profiler at the Argonne Weather Observatory (lower left), and its vertical beam measurements (right panels) on 2013 April 18.

FIG. 7. Best simulated (a) geopotential height (m) at 500hPa, (b) sea level pressure (hPa), and (c) horizontal wind fields ( $\mathrm{m} \mathrm{s}^{-1}$; vector) and vertical velocity $\left(\mathrm{m} \mathrm{s}^{-1}\right.$; color shading) at 850 hPa at 0600 UTC 18 April 2013.

FIG. 8. Bestrun simulations (as per Table 1) for integrated vapor transport $\left(\mathrm{kg} \mathrm{m}^{-1} \mathrm{~s}^{-1}\right.$, from1000 to $300 \mathrm{hPa}$ ) at $0600 \mathrm{UTC}$ (top) and $1200 \mathrm{UTC}$ (bottom) on 18 April 2013. 
893 FIG. 9. (a) Locations and daily precipitation accumulation (in mm, as per color scale on the right) 894 for raingauges in Domain d03 with 24-h accumulated precipitation heavier than $80 \mathrm{~mm}$

FIG. 11. Observed (a) and simulated (b-f) 24-h accumulatedprecipitation (mm) for the five parameterization experiments in Table 1, over Domain d03. The observation field is from NWS RFC (2013).

911 Fig. 12. (b) Spatio-temporal patterns of 1-h precipitation(mm) on 18 April 2013 (0000, 0300,

FIG. 12. (a) Spatio-temporal patterns of 1-h precipitation(mm) on 18 April 2013 (0000, 0300, 0600, 0900, 1200,1500, 1800, and 2100UTC). Observations (NWS RFC data) are on the left in each pair, and control simulationsare on the right.

913 Test 2 (WDM-KF)is in the right two panels. 
914 Fig. 12. (c) Spatio-temporal patterns of 1-h precipitation(mm) on 18 April 2013 (0000, 0300,

915

916

917

918

919

920

921

922

923

924

925

926

927

928

929

930

931

932 0600, 0900, 1200, 1500, 1800, and 2100UTC). Test 3 (WSM-GD) isin the left two panels; Test 4 (Morr-GD) is in the right two panels.

Fig. 13. Diurnal variation of spatially-averaged rainfall rate (in $\mathrm{mm} \mathrm{h}^{-1}$ ) for (a) Domain d03 and (b) the Chicago area. NWS RFC observations and WRF simulations on 18 April 2013.

Fig. 14. Time-height cross section of radar-detected and model-simulated horizontal wind fields (knots) at Argonne during 2000 UTC 17 April to 1600 UTC 18 April 2013.

Fig. 15. Observed and simulated temporal variations (from 2000 UTC 17 April to 1600 UTC 18 April) of rainfall intensity $\left(\mathrm{mm} \mathrm{h}^{-1}\right)$ at Argonne. Each bar is plotted at time intervals of 1 minute for the observation data and at 10 minutes for the model outputs. The right-corner numbers in each simulation plotcorrespond to the site percent bias (SPB, as per Eq. 3)for 24-h accumulated precipitation from 1200 UTC 17 April to 1200 UTC 18 April. The numbers below the SPB value correspond to the mean precipitation intensities $\left(\mathrm{mm} \mathrm{h}^{-1}\right)$ during the period displayed in the $\mathrm{X}$ axis.

Fig. 16. Time-height cross section of rain water mixing ratio $\left(\mathrm{g} \mathrm{kg}^{-1}\right)$ at Argonne during 2000 UTC 17 April to 1600 UTC 18 April 2013.

Fig. 17. Time-height cross section of water vapor mixing ratio (left, $\mathrm{g} \mathrm{kg}^{-1}$ ) and ascending motion (right, $\mathrm{m} \mathrm{s}^{-1}$ ) at Argonne during the period from 2000 UTC 17 April to 1600 UTC 18 April 2013. 
TABLE 1. The microphysics schemes and cumulus parameterizations used for the five WRF simulations in this study.

\begin{tabular}{cccc}
\hline \hline & Experiment name & Microphysics & Cumulus parameterization \\
\hline Control & Morr-GD & Morrison & Grell-Dévényi \\
Test 1 & Morr-KF & Morrison & Kain-Fritsch \\
Test 2 & WDM-KF & WDM6 & Kain-Fritsch \\
Test 3 & WSM-GD & WSM6 & Grell-Dévényi \\
Best & WSM-KF & WSM6 & Kain-Fritsch \\
\hline
\end{tabular}


TABLE 2. Observed and simulated 24-h accumulated precipitation (in $\mathrm{mm}$ ) averaged over Domain d03 (Fig. 10a) and Chicago area (Fig. 10b).

\begin{tabular}{lcccccc}
\hline & $\begin{array}{c}\text { Observation (NWS } \\
\text { RFC 2013) }\end{array}$ & $\begin{array}{c}\text { Best } \\
\text { WSM-KF }\end{array}$ & $\begin{array}{c}\text { Test 1 } \\
\text { Morr-KF }\end{array}$ & $\begin{array}{c}\text { Test 2 } \\
\text { WDM-KF }\end{array}$ & $\begin{array}{c}\text { Test 3 } \\
\text { WSM-GD }\end{array}$ & $\begin{array}{c}\text { Control } \\
\text { Morr-GD }\end{array}$ \\
\hline $\begin{array}{c}\text { Domain } \\
\text { d03 }\end{array}$ & 47.1 & 45.3 & 43.6 & 42.9 & 30.8 & 35.4 \\
$\begin{array}{c}\text { Chicago } \\
\text { area }\end{array}$ & 96.8 & 79.5 & 69.8 & 50.9 & 32.4 & 43.6 \\
\hline
\end{tabular}


TABLE3. Spatial correlations between observations and the five WRF simulations in Figure 12.

\begin{tabular}{ccc}
\hline & Experiment name & Spatial correlation \\
\hline Control & Morr-GD & 0.39 \\
Test 1 & Morr-KF & 0.45 \\
Test 2 & WDM-KF & 0.34 \\
Test 3 & WSM-GD & 0.31 \\
Best & WSM-KF & 0.42 \\
\hline
\end{tabular}


TABLE 4. Regional average bias (RAB, as per Eq.2) over Iowa (IA), Illinois (IL), and Missouri (MO), for different spin-up times, and using the BEST model parameterization. All RAB values are calculated using the same 24h period, from April 1712 UTC to April 1812 UTC, 2013. The last row corresponds to the mean $\mathrm{RAB}$ value for all initial times except the $4^{\text {th }}$ row (the initialization time used in Fig. 11, in bold).

\begin{tabular}{ccccc}
\hline $\begin{array}{c}\text { Initialization } \\
\text { Time (UTC) }\end{array}$ & $\begin{array}{c}\text { Spin-up } \\
\text { Time (hours) }\end{array}$ & IA & $\begin{array}{c}\text { RAB (mm) } \\
\text { IL }\end{array}$ & MO \\
\hline 2013 Apr.14 1800 & 66 & -23.8 & -30.6 & -19.9 \\
2013 Apr.15 0000 & 60 & -42.2 & -23.1 & -7.1 \\
2013 Apr.15 0600 & 54 & -35.5 & -26.3 & -17.8 \\
$\mathbf{2 0 1 3}$ Apr.15 1200 & $\mathbf{4 8}$ & $\mathbf{- 3 2 . 1}$ & $\mathbf{- 1 4 . 1}$ & $\mathbf{- 1 6 . 6}$ \\
2013 Apr.15 1800 & 42 & -36.2 & -5.9 & 3.5 \\
2013 Apr.16 0000 & 36 & -25.9 & -12.9 & -8.1 \\
\hline Ensemble Mean & & -32.7 & -19.8 & -9.9 \\
\hline
\end{tabular}


TABLE 5. Site percent bias (SPB, as per Eq.3) for the model parameterizations in Table 1, at the nine simulation points closest to the Argonne site. The first column corresponds to the SPB values in Fig. 16.

\begin{tabular}{|c|c|c|c|c|c|}
\hline Grid & & & $\overline{\text { SPB (\%) }}$ & & \\
\hline Point & Best & Test 1 & Test 2 & Test 3 & Control \\
\hline Closest & -3.65 & -17.1 & -33.3 & -53.2 & -73.9 \\
\hline 2nd & -5.64 & 9.1 & -79.7 & -97.5 & -94.9 \\
\hline $3 \mathrm{rd}$ & -33.8 & -95.1 & -89.8 & -98.6 & -90.2 \\
\hline 4th & -84.8 & -98.7 & -99.5 & -99.9 & -97.2 \\
\hline 5 th & -97.9 & -98.8 & -96.8 & -98.1 & -99.9 \\
\hline 6 th & -35.8 & -24.0 & 2.6 & -46.7 & -22.4 \\
\hline 7 th & 100.0 & -48.8 & -63.0 & -60.1 & -25.2 \\
\hline 8th & -43.3 & -66.8 & -55.4 & -15.9 & -51.8 \\
\hline 9th & -87.5 & -66.0 & -92.7 & -22.6 & -34.3 \\
\hline Mean & -32.5 & -56.2 & -67.5 & -65.8 & -65.5 \\
\hline
\end{tabular}



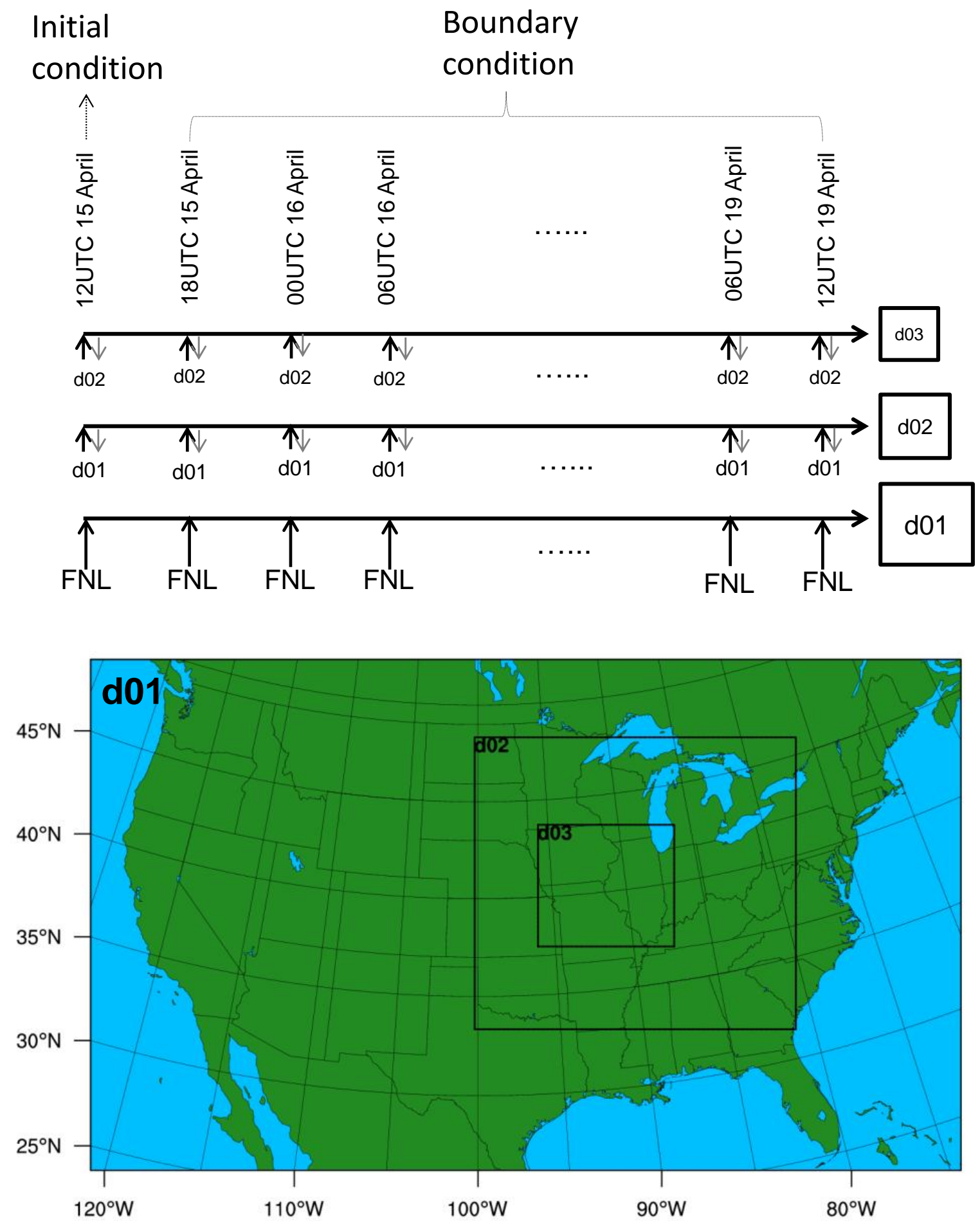

FIG. 1.Temporal (top) and spatial (bottom) configuration of three WRF nested domains, d01, d02, and d03, using FNL reanalysis as initial and boundary conditions for the d01 domain. 
24h accumulated precipitation

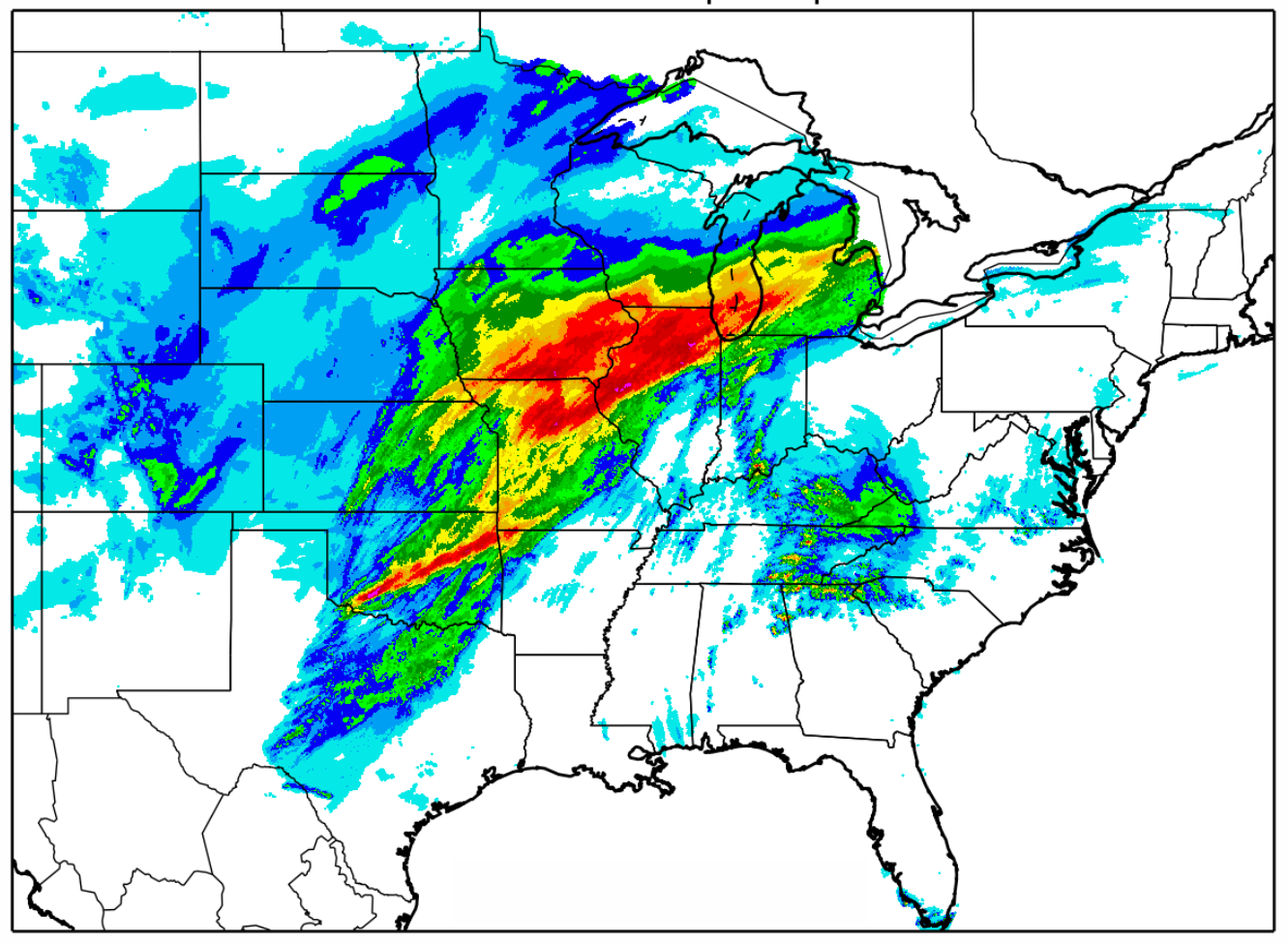

$\mathrm{mm}$

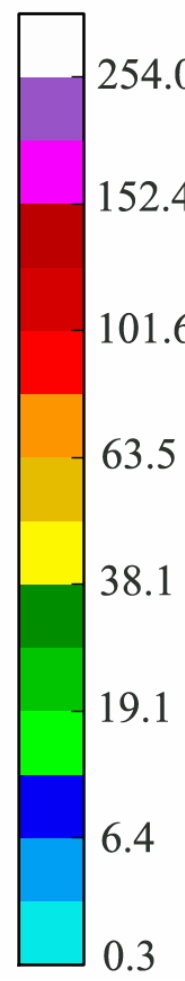

Fig. 2. 24-h accumulatedprecipitation data (mm) from 1200 UTC 17 April to 1200 UTC 18 April (NWSRFC 2013). Image courtesy of Dr. Jonathan Helmus (Argonne National Laboratory). 
(a) $500 \mathrm{hPa}$ geopotential height (m)

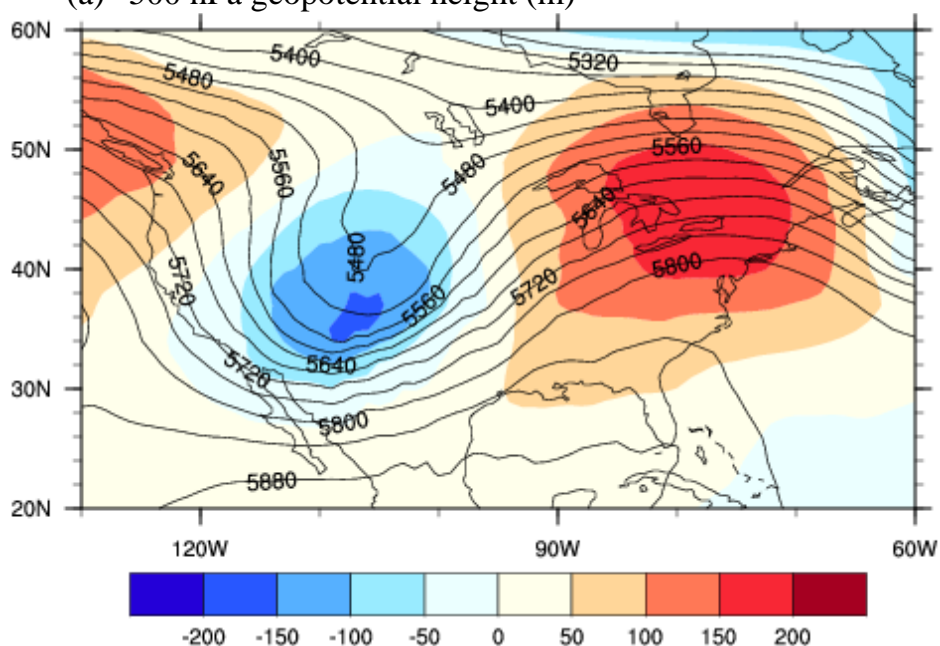

(c) Precipitable water (mm)

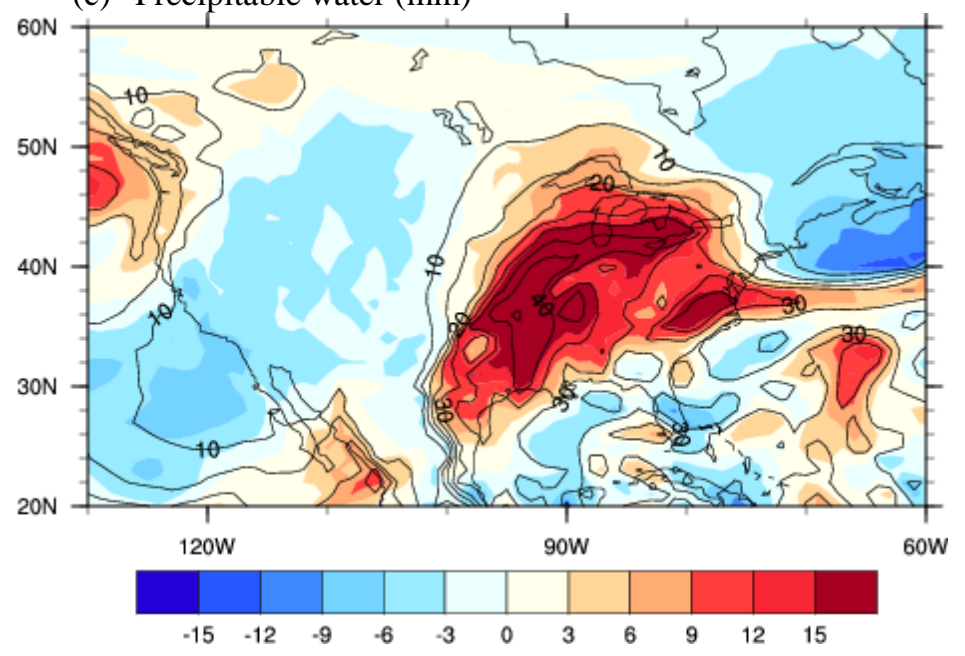

(b) $850 \mathrm{hPa}$ winds $(\mathrm{m} / \mathrm{s})$

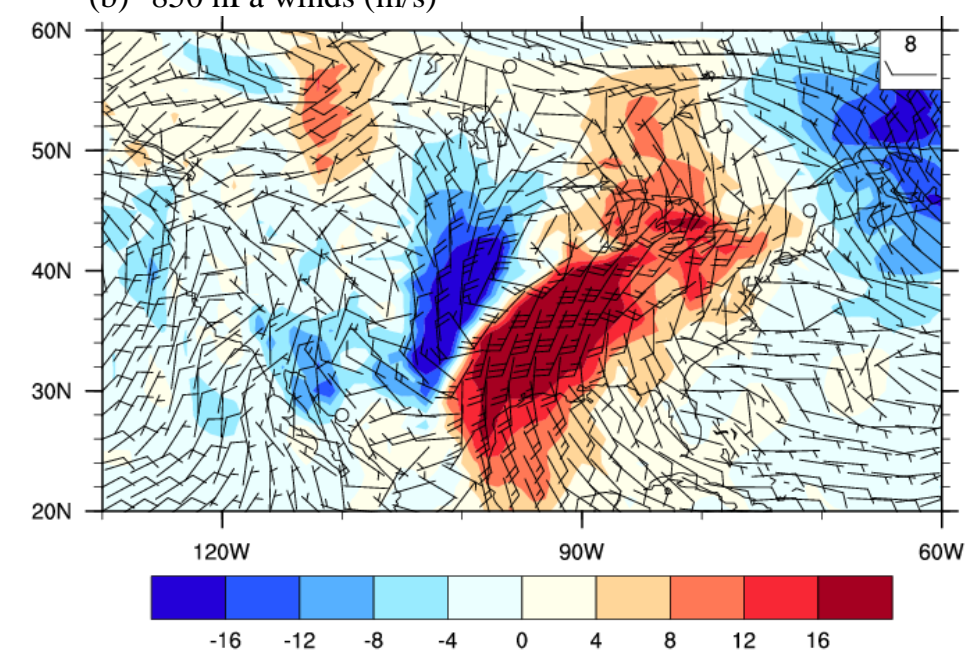

(d) Sea level pressure $(\mathrm{hPa})$

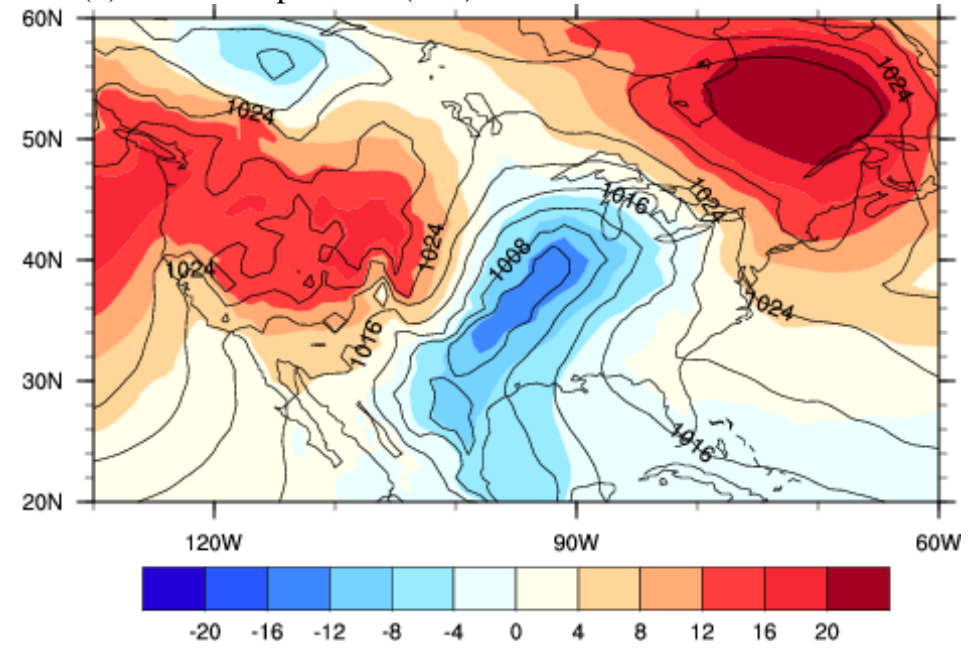

FIG. 3.NCEP-FNL reanalysis data valid at 0600 UTC 18 April 2013, showing (a) $500 \mathrm{hPa}$ geopotential height and anomalies (m); (b) 850 hPa winds and v-wind anomalies ( $\left.\mathrm{m} \mathrm{s}^{-1}\right)$; (c) precipitable water and anomalies (mm); (d) sea level pressure and anomalies (hPa).Magnitudes are plotted as black isolines or wind barbs, and April-2013 anomalies are plotted as color shades. 


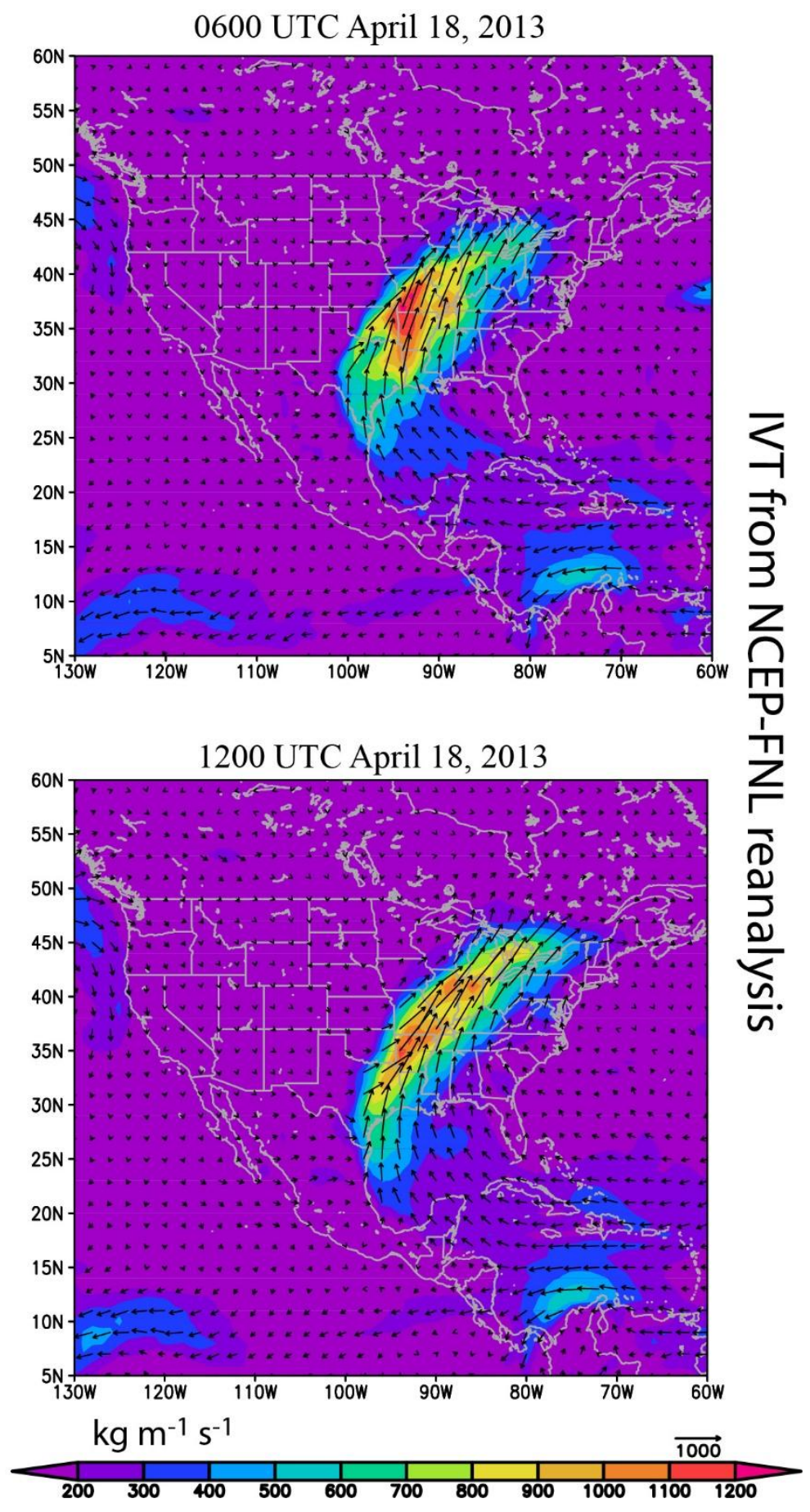

FIG. 4. Integrated vapor transport $\left(\mathrm{kg} \mathrm{m}^{-1} \mathrm{~s}^{-1}\right.$, from 1000 to $300 \mathrm{hPa}$ ) at $0600 \mathrm{UTC}$ (top) and 1200 UTC (bottom) on 18 April 2013. Data from NCEP-FNL reanalysis. 


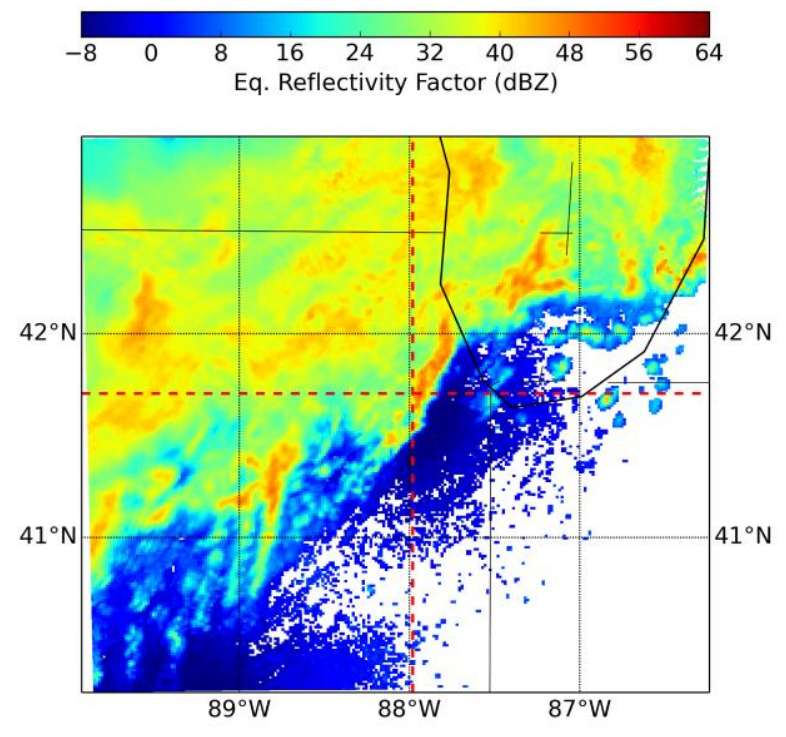

Sliced at 2500.0 meters agl at 09:22 UTC on 18 Apr 2013
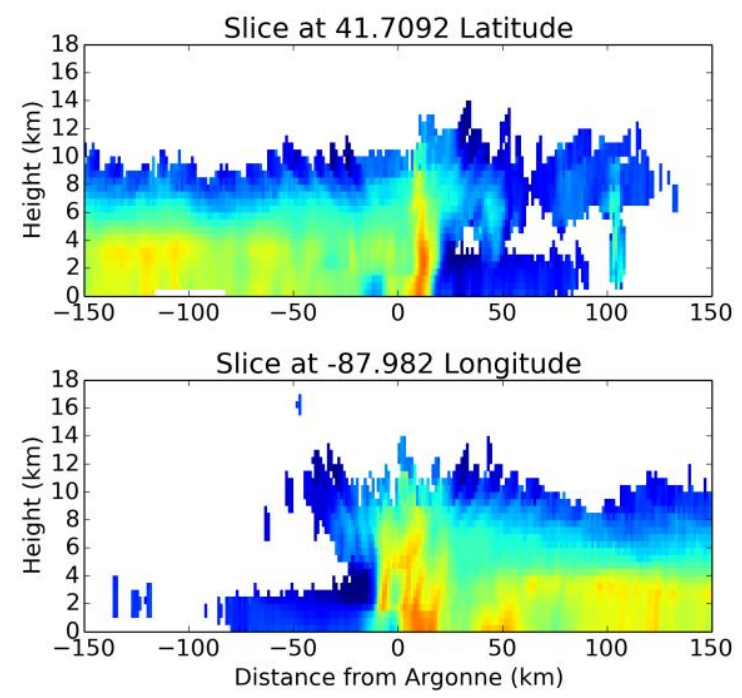

FIG. 5. Field of equivalent reflectivityfactor over the Chicago region.Data from NEXRAD WSR88D radars. Image courtesy of Dr. Scott Collis (Argonne National Laboratory). 


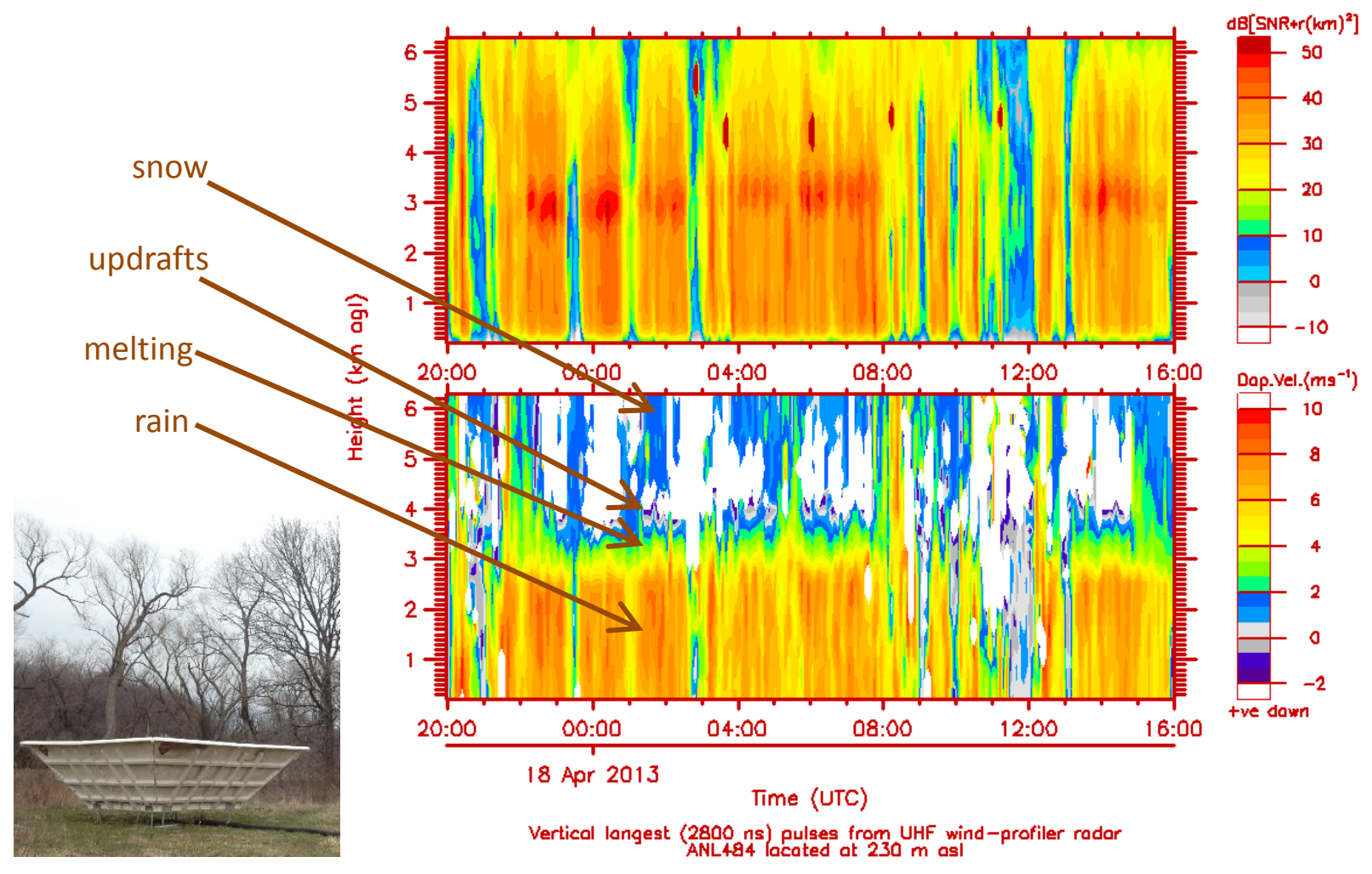

FIG. 6. The UHF radar wind profiler at the Argonne Weather Observatory (lower left), and its vertical beam measurements (right panels) on 2013 April 18. 
(a) $500 \mathrm{hPa}$ geopotential height (m)

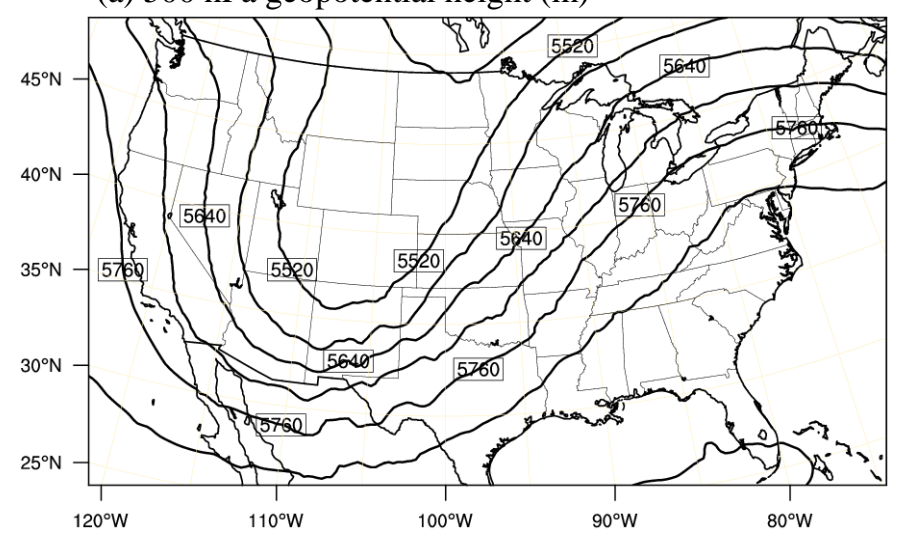

(b) Sea level pressure (hPa)

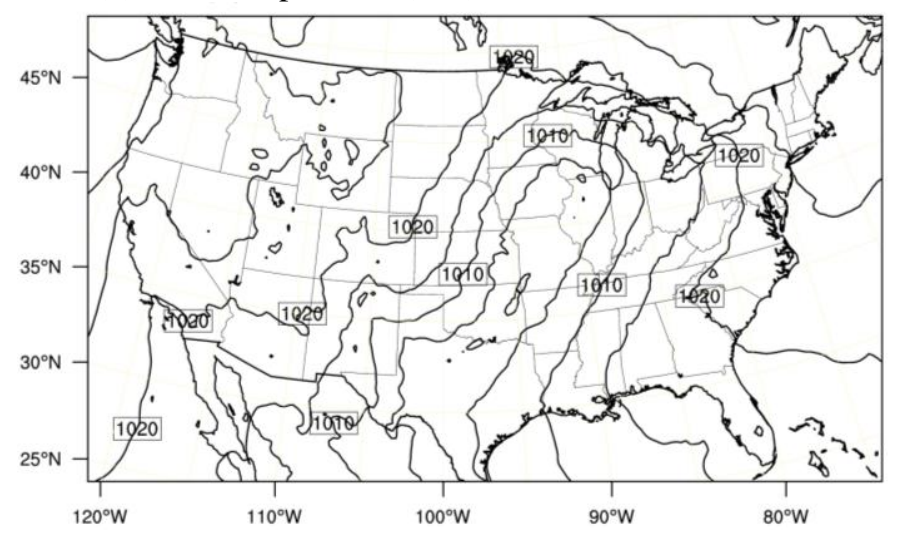

(c) $850 \mathrm{hPa}$ winds $(\mathrm{m} / \mathrm{s})$

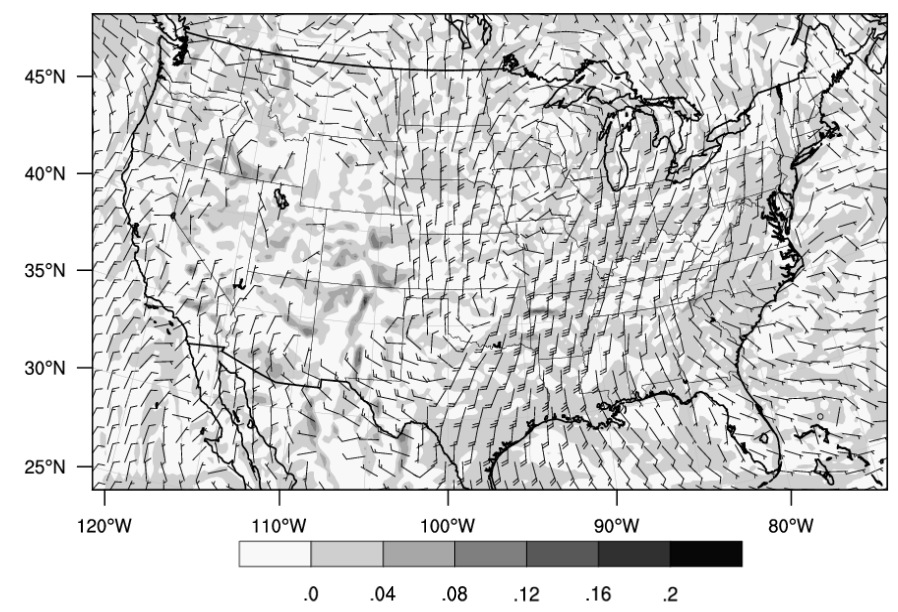

FIG. 7. Best simulated (a) geopotential height (m) at $500 \mathrm{hPa}$, (b) sea level pressure (hPa), and (c) horizontal wind fields ( $\mathrm{m} \mathrm{s}^{-1}$; vector) and vertical velocity ( $\mathrm{m} \mathrm{s}^{-1}$; color shading) at $850 \mathrm{hPa}$ at 0600 UTC 18 April 2013. 


\section{WRF Best simulations}
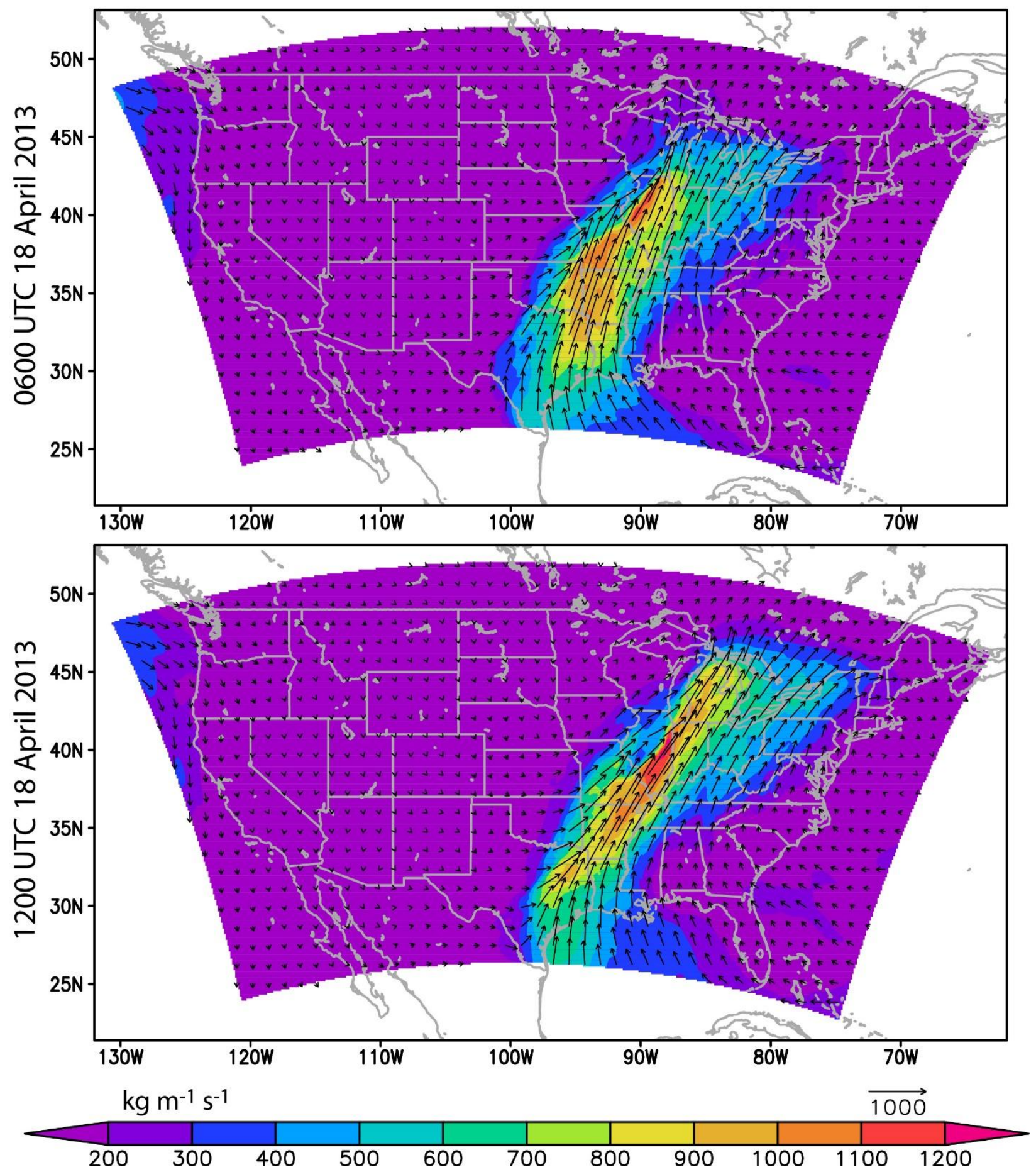

FIG. 8. Best run simulations (as per Table 1) for integrated vapor transport $\left(\mathrm{kg} \mathrm{m}^{-1} \mathrm{~s}^{-1}\right.$, from 1000 to $300 \mathrm{hPa}$ ) at $0600 \mathrm{UTC}$ (top) and $1200 \mathrm{UTC}$ (bottom) on 18 April 2013. 

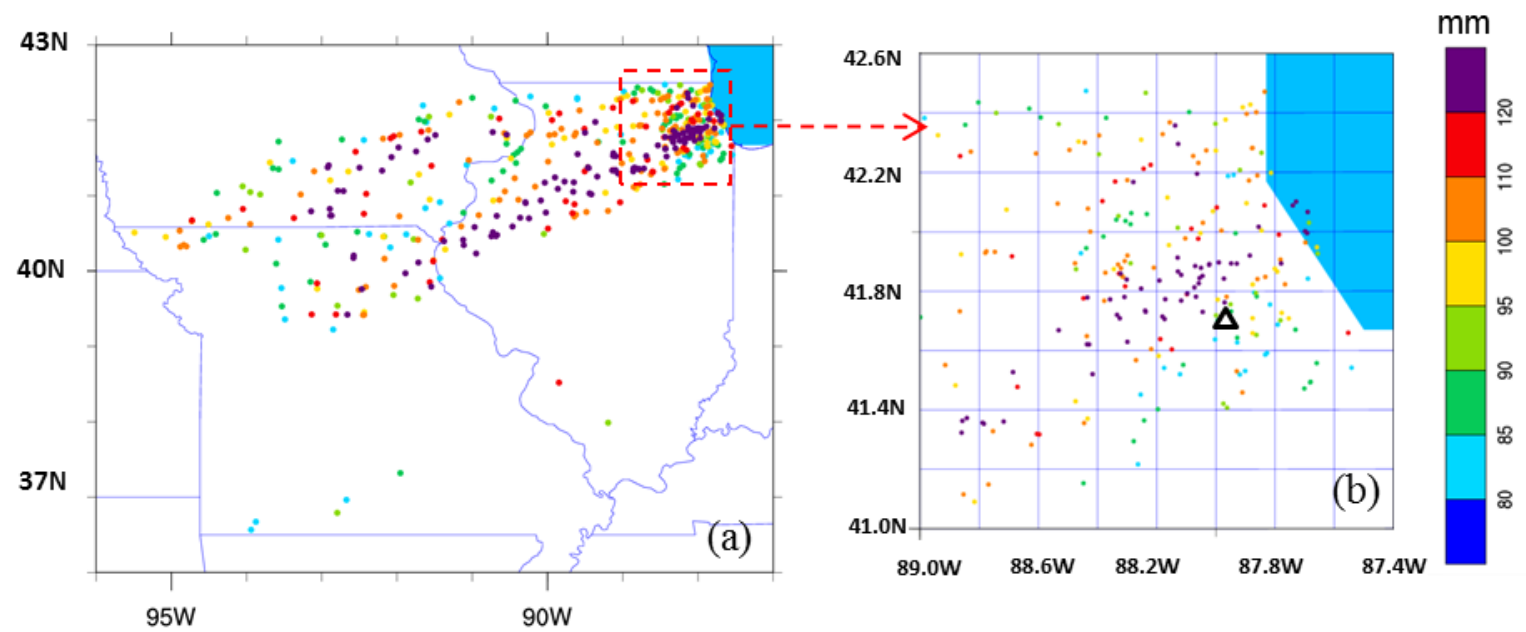

FIG. 9. (a) Locations and daily precipitation accumulation (in mm, as per color scale on the right) for rain gauges in Domain d03 with 24-h accumulated precipitation heavier than $80 \mathrm{~mm}$ across Iowa, Missouri, and Illinois. (b) Enlarged Chicago area of the red box in (a), with a black triangle marking the approximate location of the Argonne National Laboratory site, which recorded $85.4 \mathrm{~mm}$ of rainfall. See Table 2 for the model domains used in this study. Data from NCDC. 
24-hr accumulated rainfall (heavier than $80 \mathrm{~mm}$ )
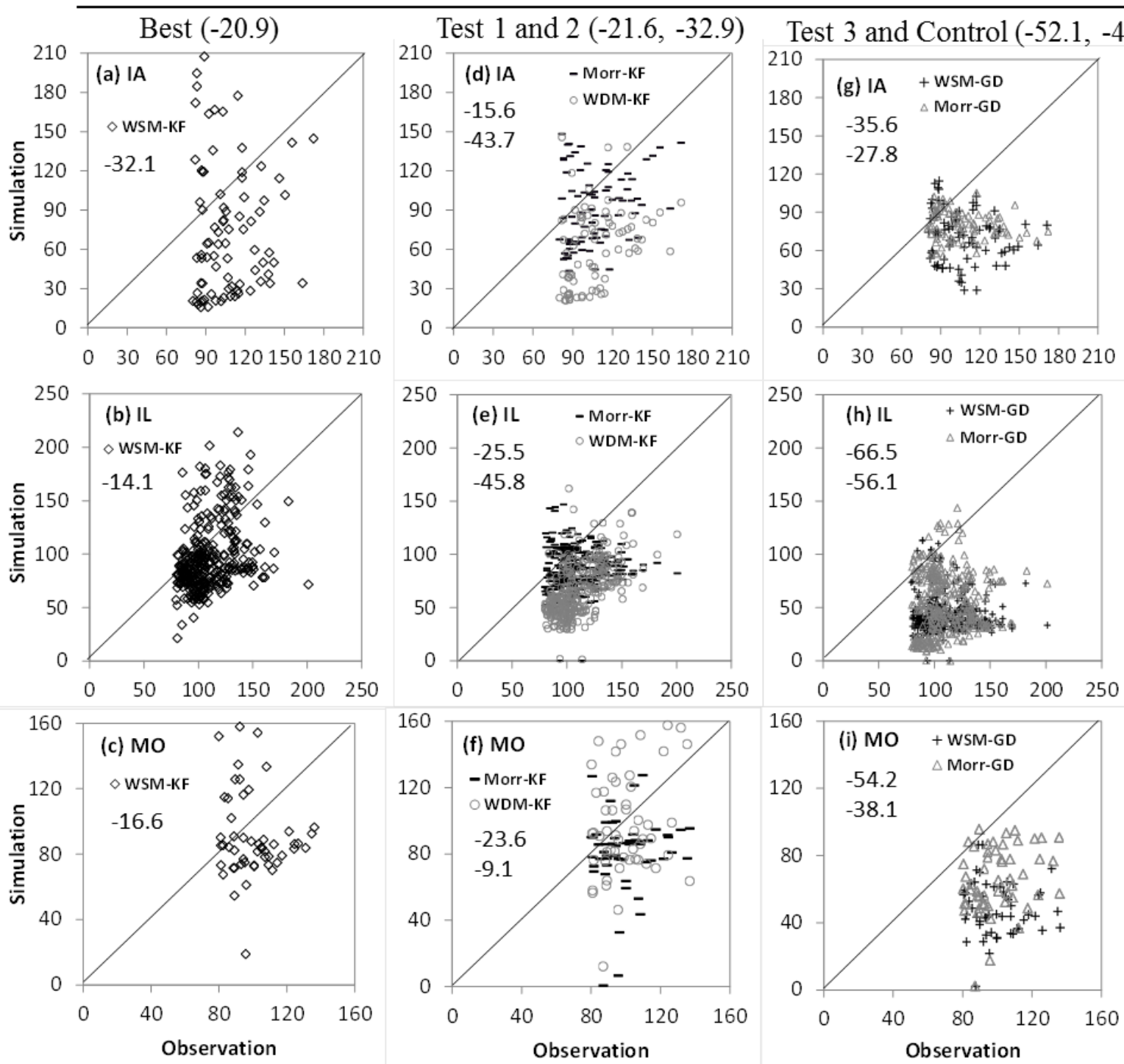

FIG. 10. Scatter plots of NCDC observed 24-h accumulated rainfall versus the WRF simulation over Iowa (first row), Illinois (second row), and Missouri (third row). (a-c) Best simulation (left panel), (d-f) Test 1 and Test 2 simulations (middle panel), (g-i) Test 3 and Control simulations (right panel). The numbers in each plot are one-state average model biases (RAB in Eq. 2), and the numbers at the tops of the panels are three-state average model biases (mm). 
(a) Observation

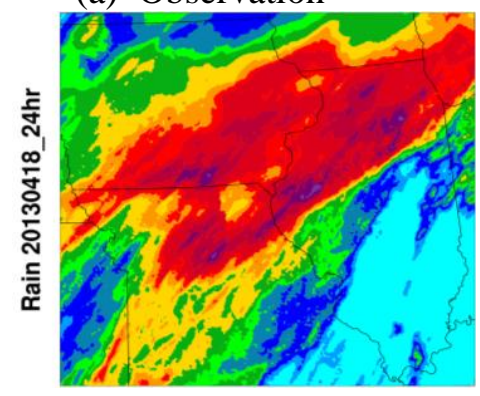

(c) Test 1: Morr-KF

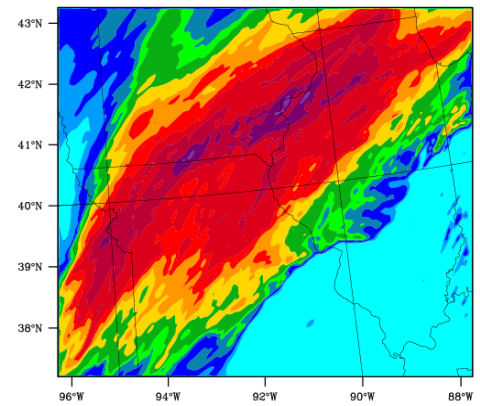

(e) Test 3: WSM-GD

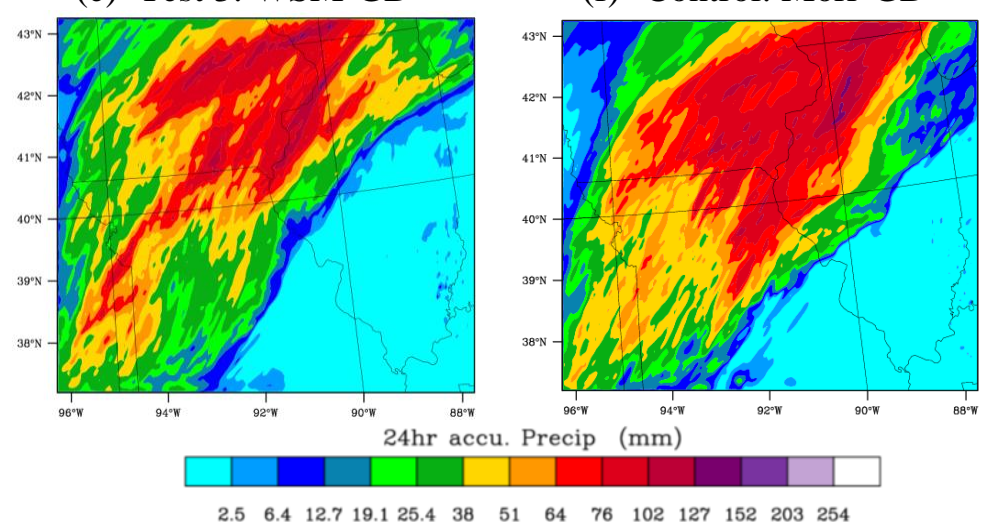

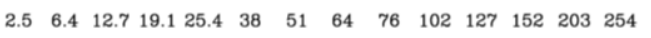

(b) Best: WSM-KF

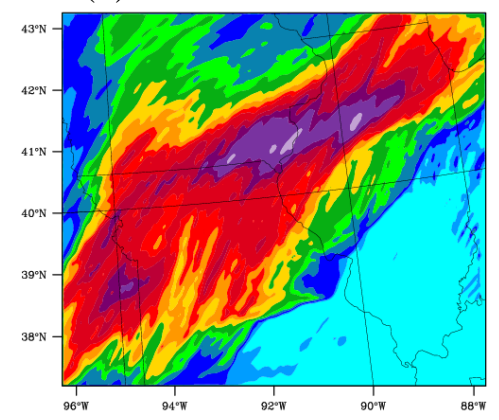

(d) Test 2: WDM-KF

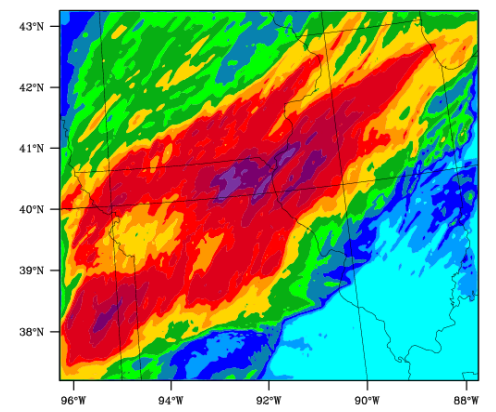

(f) Control: Morr-GD

FIG. 11. Observed (a) and simulated (b-f) 24-h accumulated precipitation ( $\mathrm{mm}$ ) for the five parameterization experiments in Table 1, over Domain d03. The observation field is from NWS RFC (2013). 


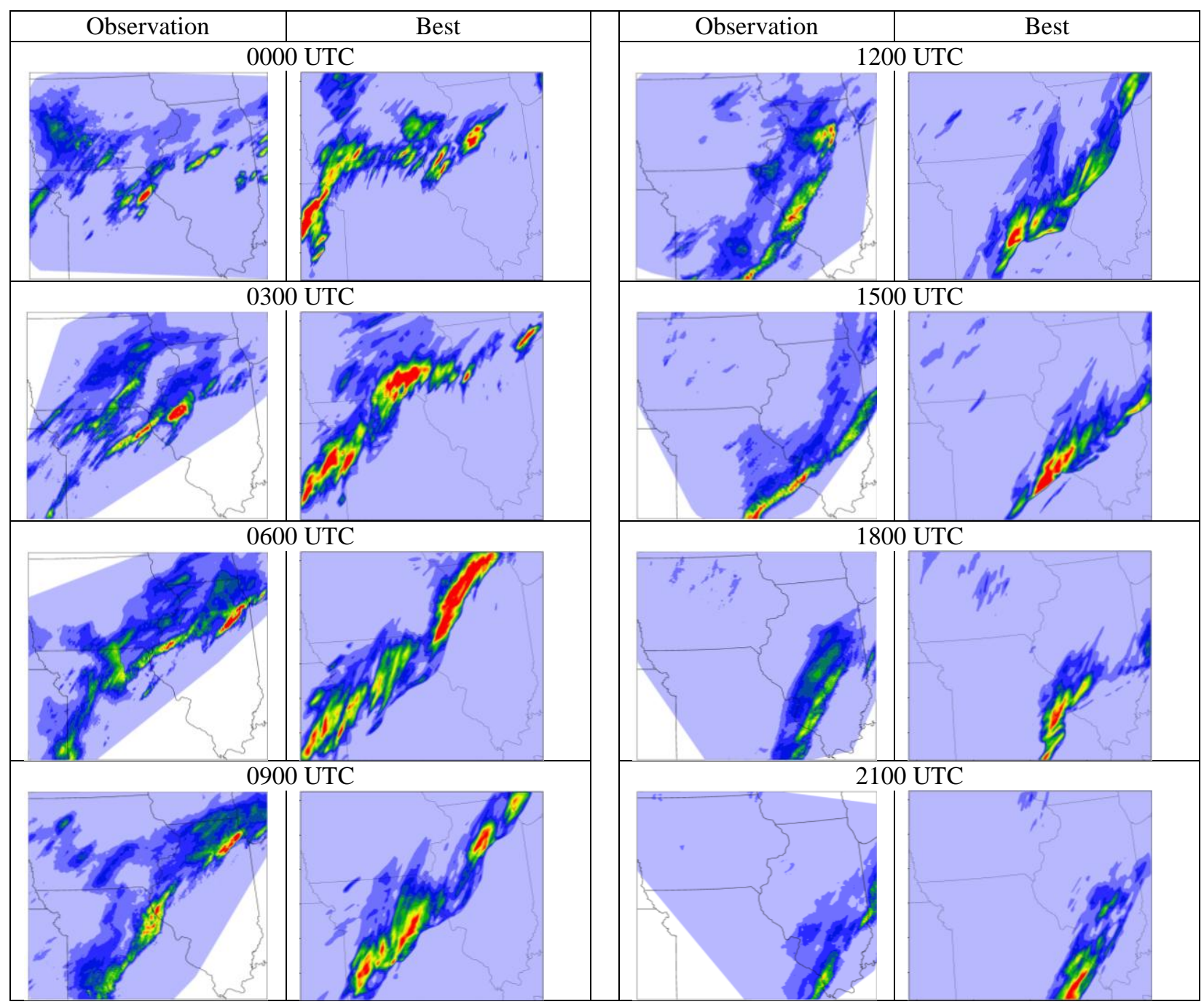




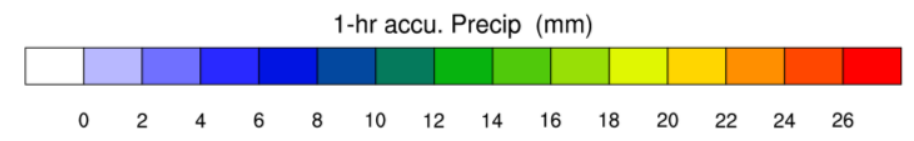

FIG. 12. (a) Spatio-temporal patterns of 1-h precipitation (mm) on 18 April 2013 (0000, 0300, 0600, 0900, 1200, 1500, 1800, and 2100 UTC). Observations (NWS RFC data) are on the left in each pair, and control simulations are on the right. 


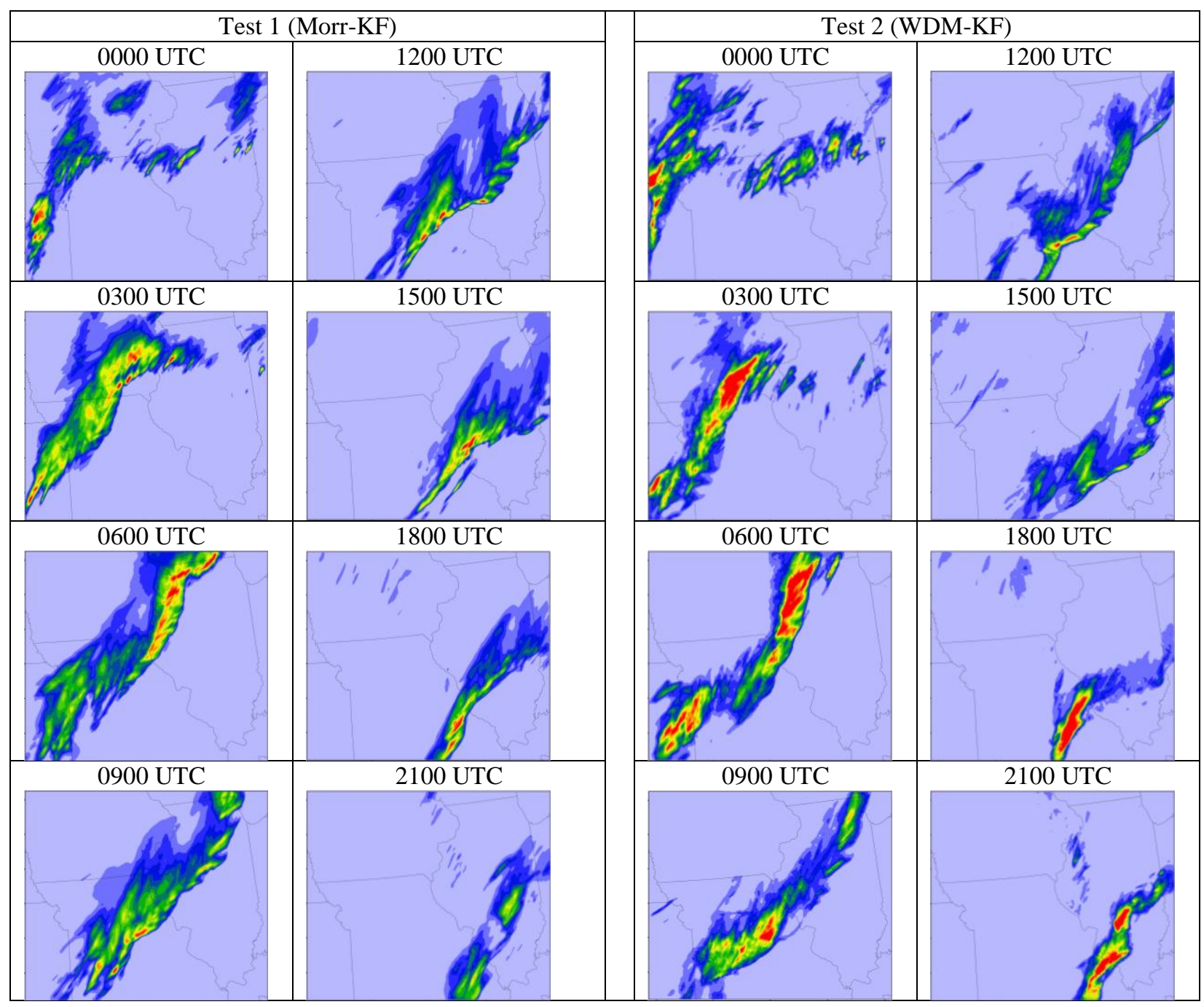




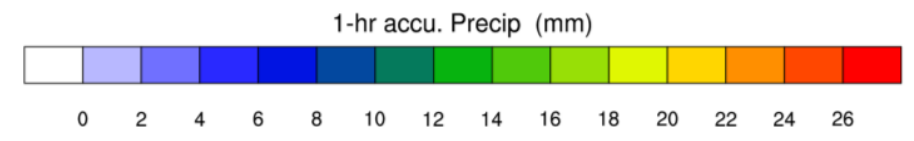

FIG. 12. (b) Spatio-temporal patterns of 1-h precipitation (mm) on 18 April 2013 (0000, 0300, 0600, 0900, 1200, 1500, 1800, and 2100 UTC). Test 1 (Morr-KF) is in the left two panels; Test 2 (WDM-KF) is in the right two panels. 


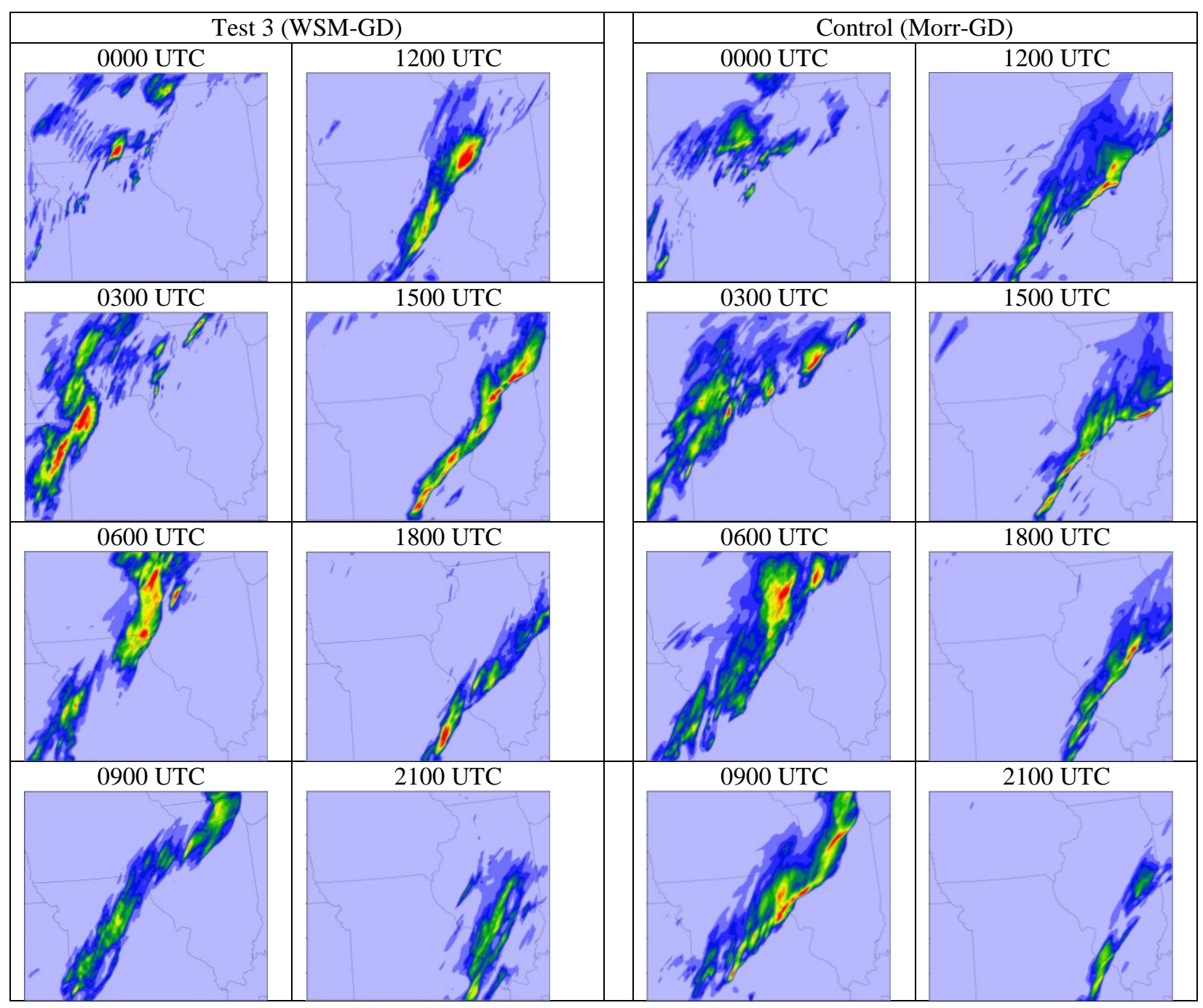




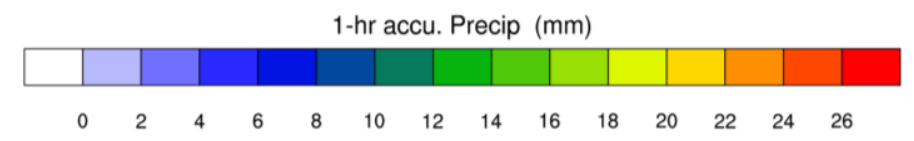

FIG. 12. (c) Spatio-temporal patterns of 1-h precipitation (mm) on 18 April 2013 (0000, 0300, 0600, 0900, 1200, 1500, 1800, and 2100 UTC). Test 3 (WSM-GD) is in the left two panels; Test 4 (Morr-GD) is in the right two panels. 

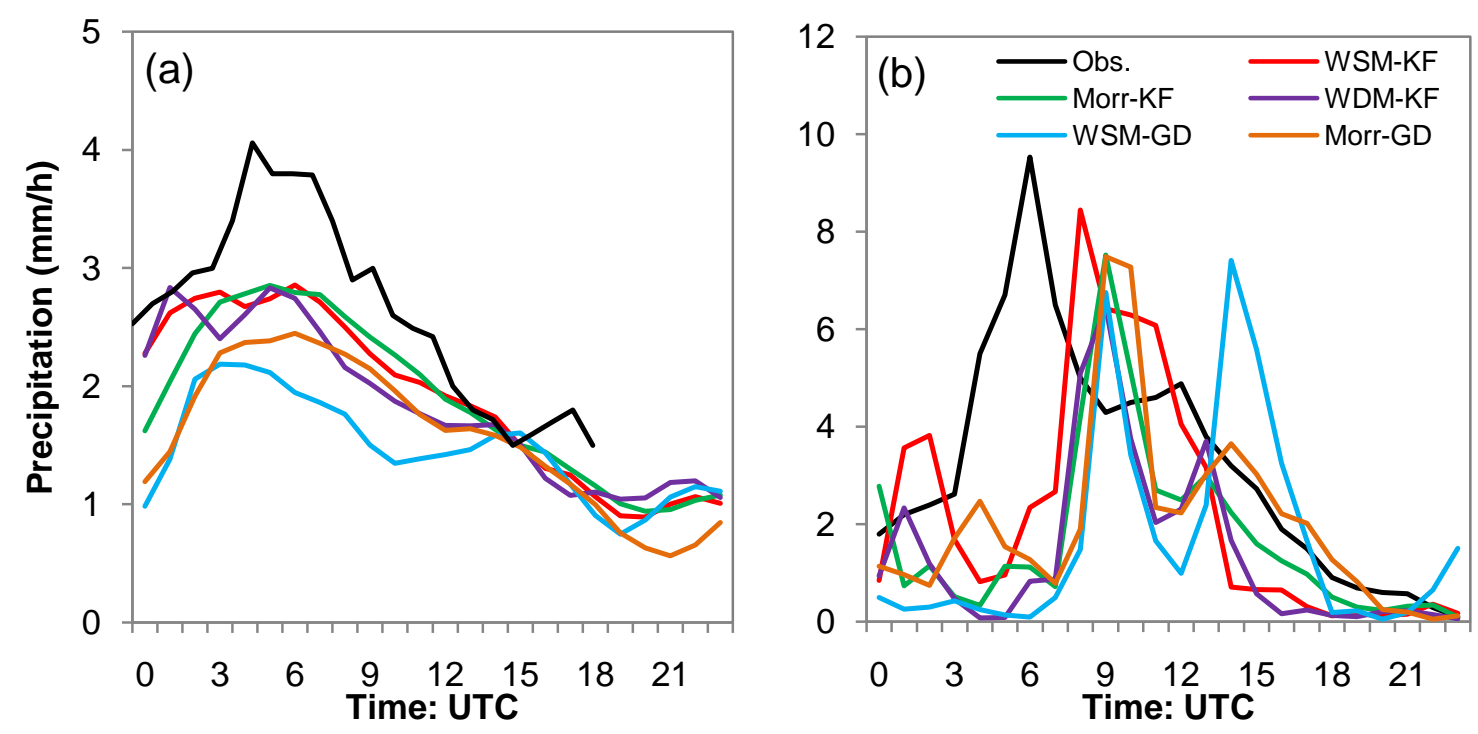

FIG. 13. Diurnal variation of spatially-averaged rainfall rate (in $\mathrm{mm} \mathrm{h}^{-1}$ ) for (a) Domain d03 and (b) the Chicago area. NWS RFC observations and WRF simulations on 18 April 2013. 

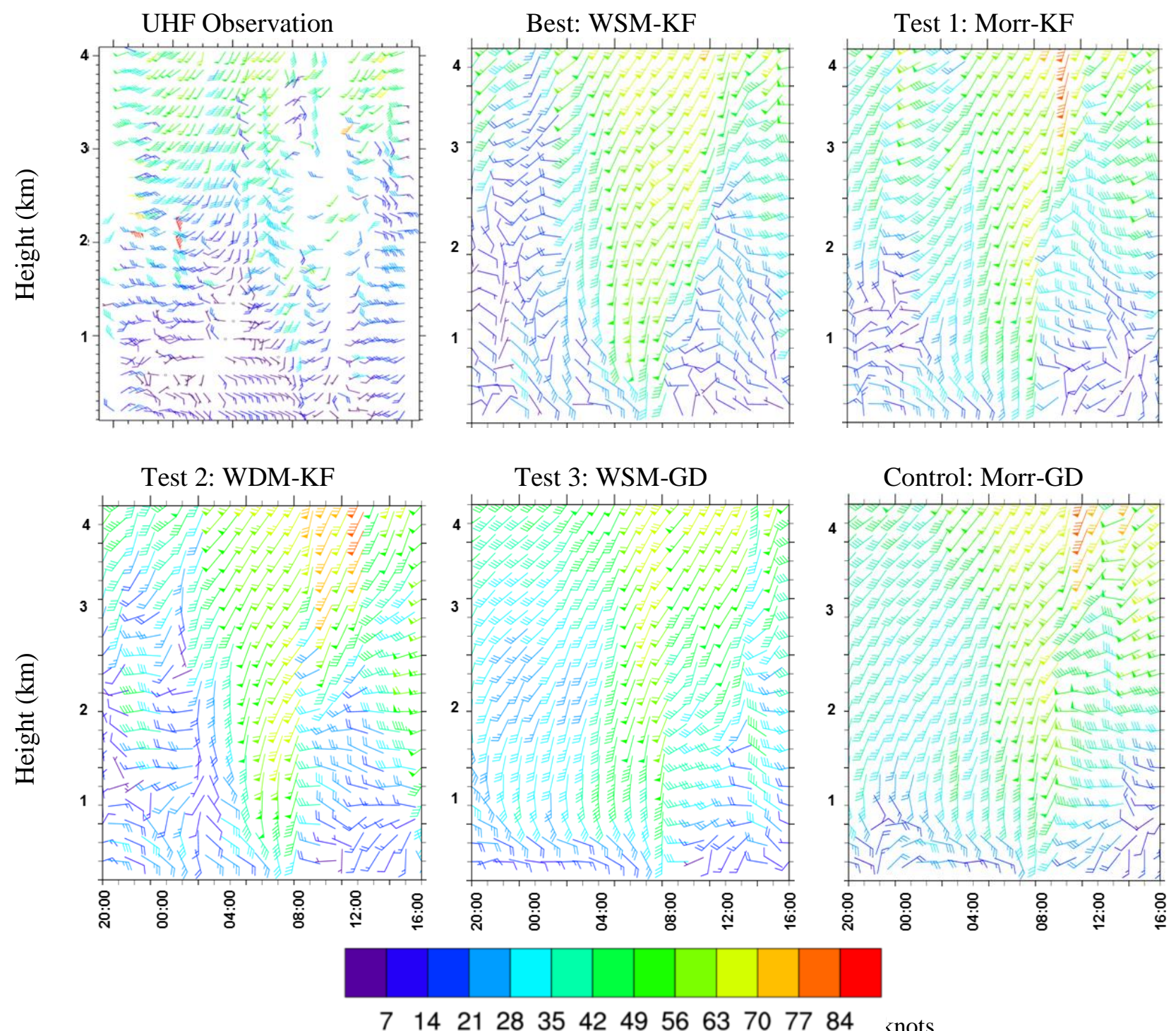

$\begin{array}{lllllllllllll}7 & 14 & 21 & 28 & 35 & 42 & 49 & 56 & 63 & 70 & 77 & 84 & \text { snots }\end{array}$

FIG. 14. Time-height cross section of radar-detected and model-simulated horizontal wind fields (knots) at Argonne during 2000 UTC 17 April to 1600 UTC 18 April 2013. 

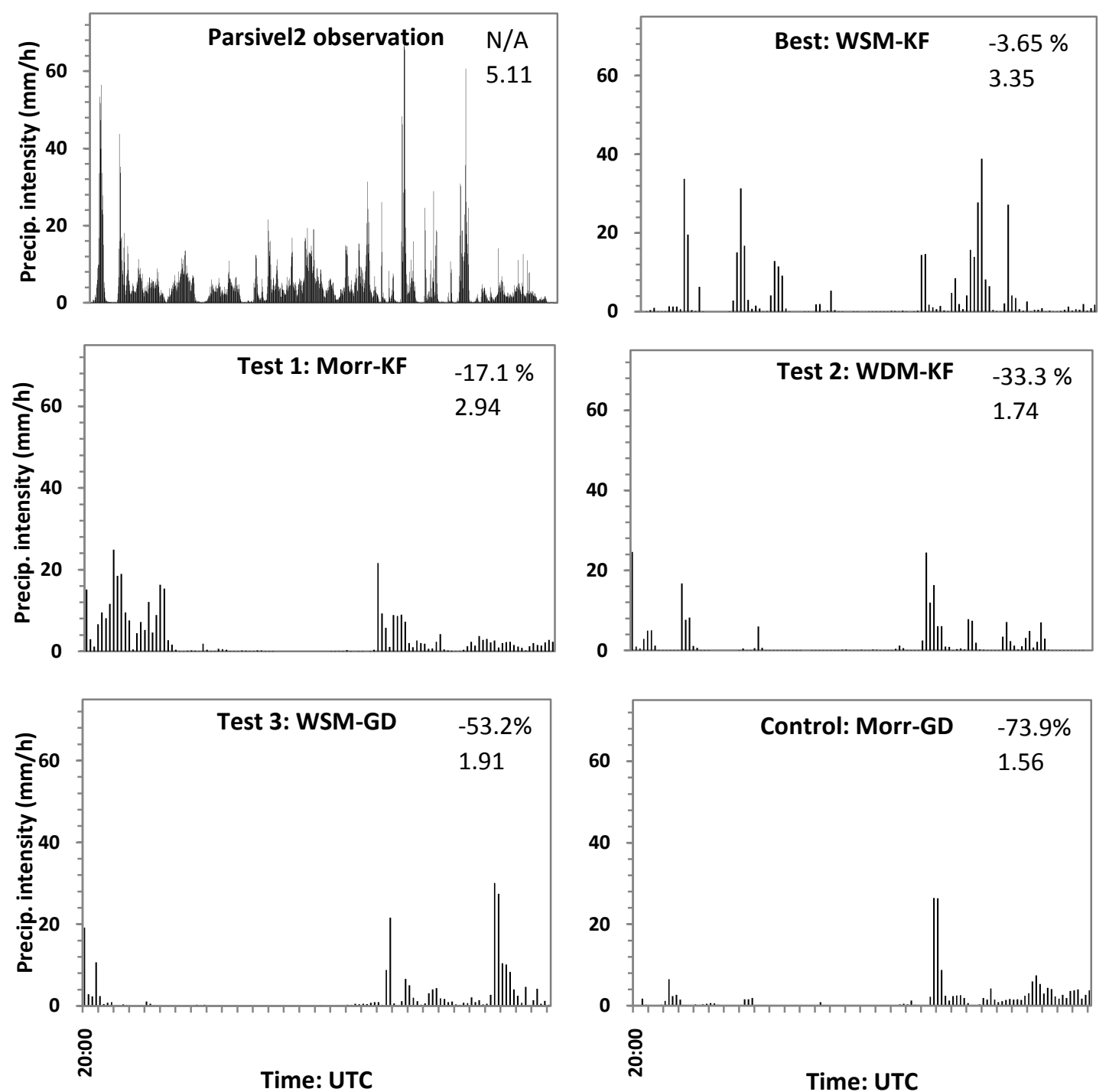

FIG. 15. Observed and simulated temporal variations (from 2000 UTC 17 April to 1600 UTC 18 April) of rainfall intensity $\left(\mathrm{mm} \mathrm{h}^{-1}\right)$ at Argonne. Each bar is plotted at time intervals of 1 minute for the observation data and at 10 minutes for the model outputs. The right-corner numbers in each simulation plot correspond to the site percent bias (SPB, as per Eq. 3)for 24-h accumulated precipitation from 1200 UTC 17 April to 1200 UTC 18 April. The numbers below the SPB value correspond to the mean precipitation intensities $\left(\mathrm{mm} \mathrm{h}^{-1}\right)$ during the period displayed in the $\mathrm{X}$ axis. 

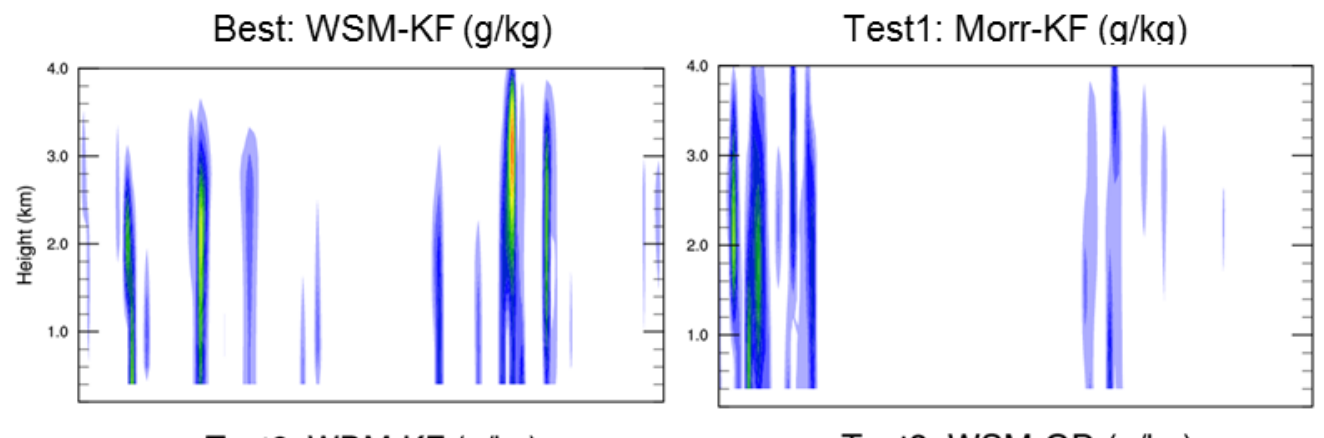

Test2: WDM-KF (g/kg)

Test3: WSM-GD $(\mathrm{g} / \mathrm{kg})$
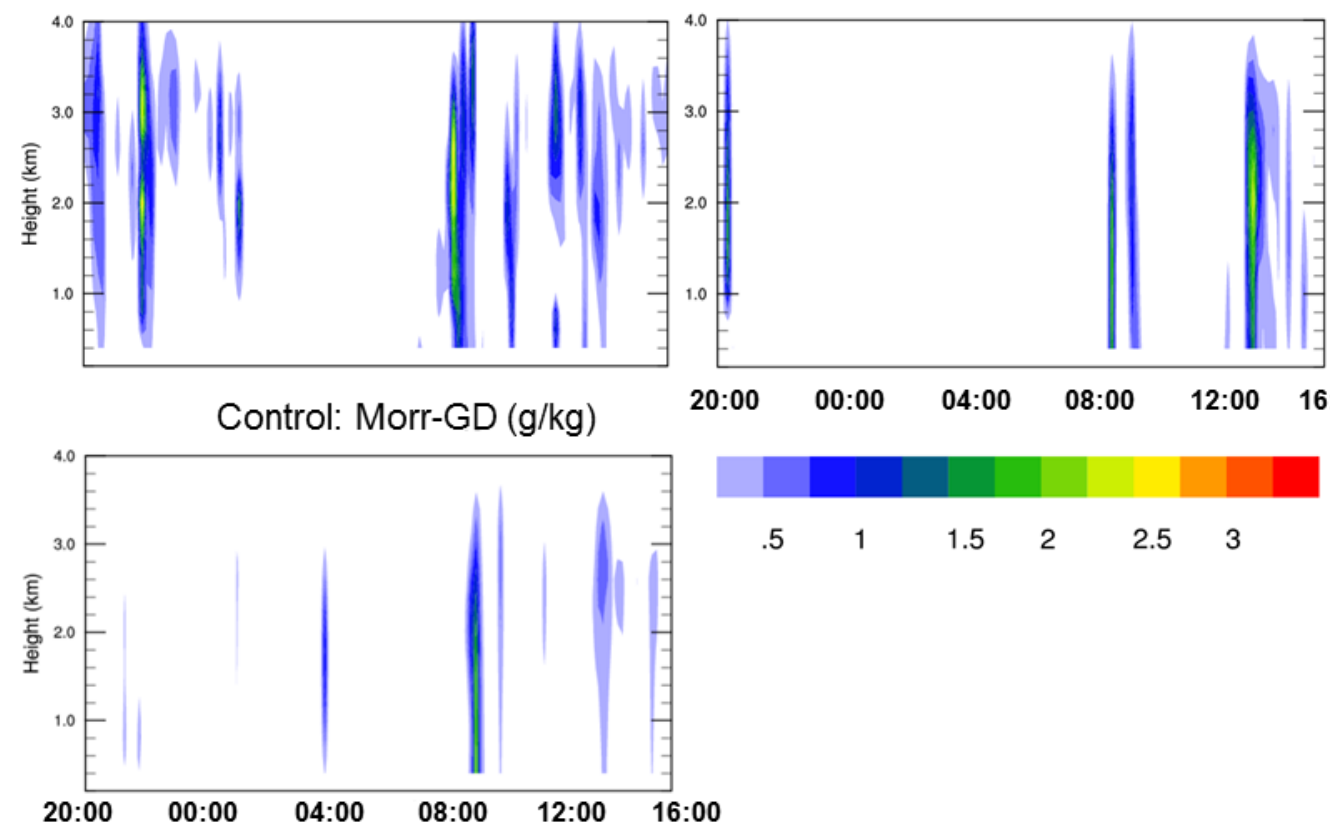

FIG. 16. Time-height cross section of rain water mixing ratio $\left(\mathrm{g} \mathrm{kg}^{-1}\right)$ at Argonne during 2000 UTC 17 April to 1600 UTC 18 April 2013. 

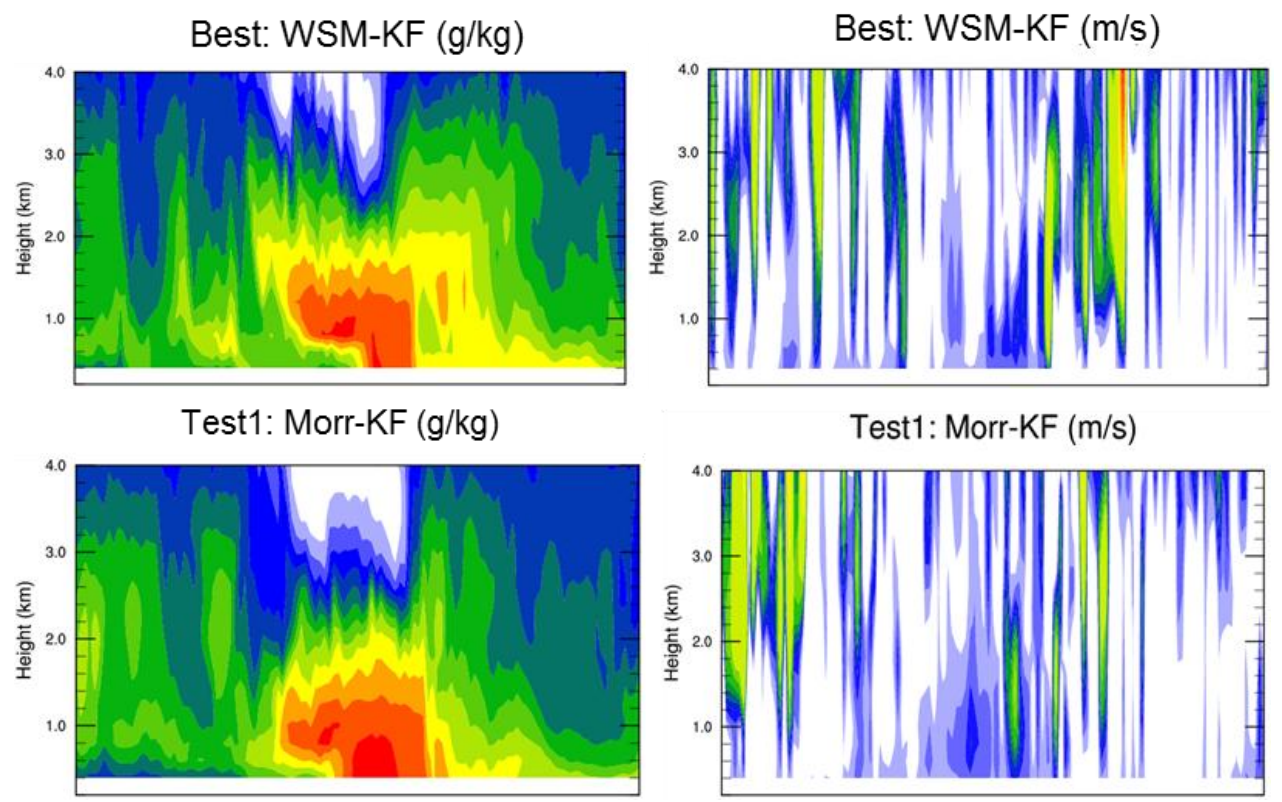

Test2: WDM-KF ( $/ \mathrm{kg})$

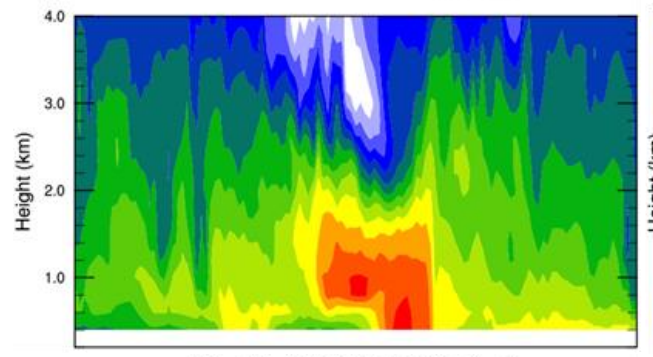

Test2: WDM-KF (m/s)
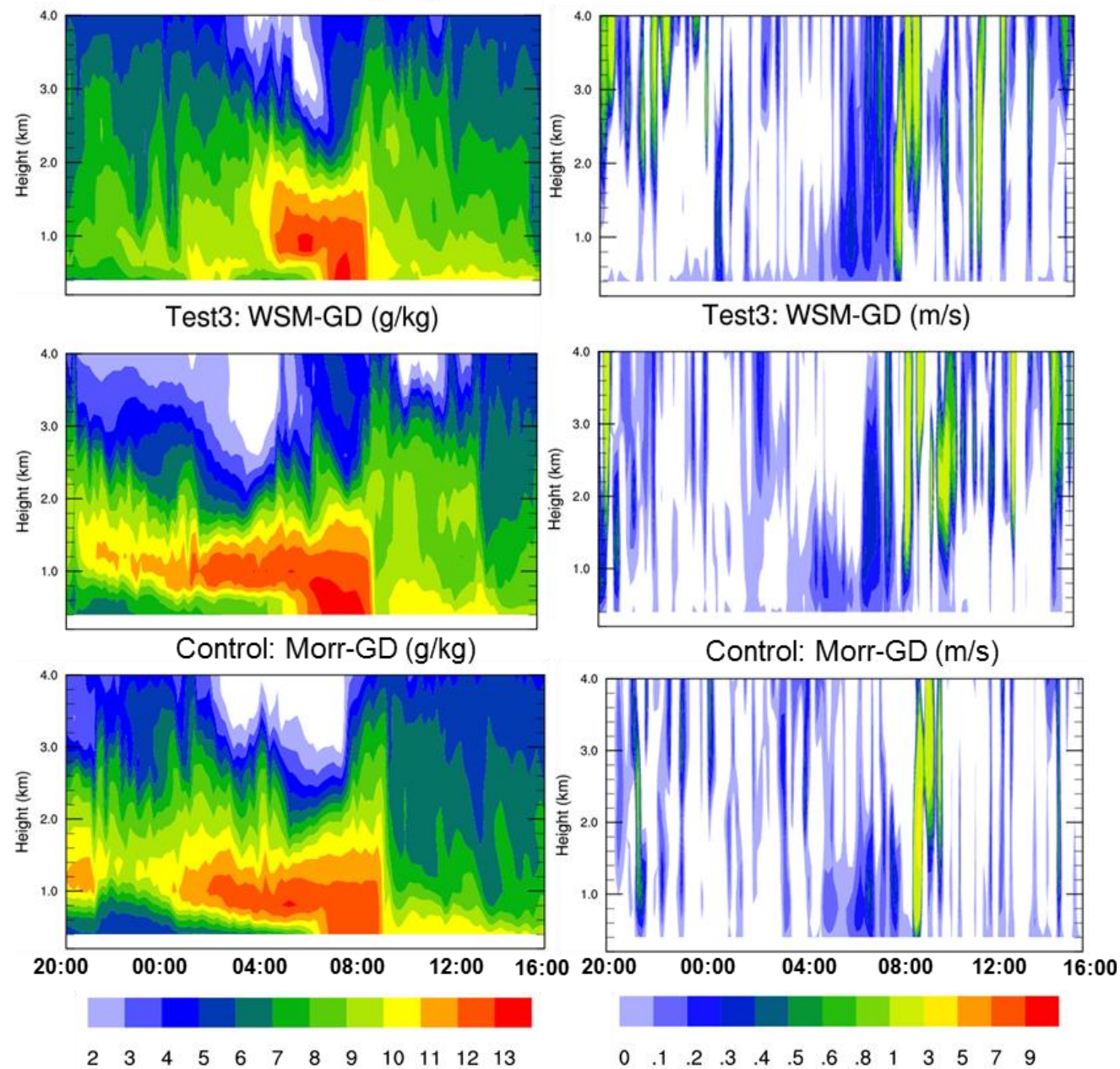
FIG. 17. Time-height cross section of water vapor mixing ratio (left, $\mathrm{g} \mathrm{kg}^{-1}$ ) and ascending motion (right, $\mathrm{m} \mathrm{s}^{-1}$ ) at Argonne during the period from 2000 UTC 17 April to 1600 UTC 18 April 2013. 